\title{
Cervical spine alignment, sagittal deformity, and clinical implications
}

\author{
A review
}

\author{
Justin K. Scheer, B.S., ${ }^{1}$ Jessica A. Tang, B.S., ${ }^{1}$ Justin S. Smith, M.D., Ph.D., ${ }^{2}$ \\ Frank L. Acosta Jr., M.D. ${ }^{3}$ Themistocles S. Protopsaltis, M.D., ${ }^{4}$ \\ Benjamin Blondel, M.D., ${ }^{5}$ Shay Bess, M.D. ${ }^{6}$ Christopher I. Shaffrey, M.D. ${ }^{2}$ \\ Vedat Deviren, M.D. ${ }^{7}$ Virginie Lafage, Ph.D. ${ }^{4}$ Frank Schwab, M.D.,${ }^{4}$ \\ Christopher P. Ames, M.D., ${ }^{8}$ AND the InTernational Spine Study Group
}

${ }^{1}$ School of Medicine, University of California, San Diego, California; ${ }^{2}$ Department of Neurosurgery, University of Virginia Health System, Charlottesville, Virginia; ${ }^{3}$ Department of Neurological Surgery, Cedars-Sinai Medical Center, Los Angeles, California; ${ }^{4}$ Department of Orthopaedic Surgery, NYU Hospital for Joint Diseases, New York, New York; ${ }^{5}$ Université Aix-Marseille, Marseille, France; ${ }^{6}$ Rocky Mountain Hospital for Children, Denver, Colorado; and Departments of ${ }^{7}$ Orthopedic Surgery and ${ }^{8}$ Neurological Surgery, University of California, San Francisco, California

\begin{abstract}
This paper is a narrative review of normal cervical alignment, methods for quantifying alignment, and how alignment is associated with cervical deformity, myelopathy, and adjacent-segment disease (ASD), with discussions of health-related quality of life (HRQOL). Popular methods currently used to quantify cervical alignment are discussed including cervical lordosis, sagittal vertical axis, and horizontal gaze with the chin-brow to vertical angle. Cervical deformity is examined in detail as deformities localized to the cervical spine affect, and are affected by, other parameters of the spine in preserving global sagittal alignment. An evolving trend is defining cervical sagittal alignment. Evidence from a few recent studies suggests correlations between radiographic parameters in the cervical spine and HRQOL. Analysis of the cervical regional alignment with respect to overall spinal pelvic alignment is critical. The article details mechanisms by which cervical kyphotic deformity potentially leads to ASD and discusses previous studies that suggest how postoperative sagittal malalignment may promote ASD. Further clinical studies are needed to explore the relationship of cervical malalignment and the development of ASD. Sagittal alignment of the cervical spine may play a substantial role in the development of cervical myelopathy as cervical deformity can lead to spinal cord compression and cord tension. Surgical correction of cervical myelopathy should always take into consideration cervical sagittal alignment, as decompression alone may not decrease cord tension induced by kyphosis. Awareness of the development of postlaminectomy kyphosis is critical as it relates to cervical myelopathy. The future direction of cervical deformity correction should include a comprehensive approach in assessing global cervicalpelvic relationships. Just as understanding pelvic incidence as it relates to lumbar lordosis was crucial in building our knowledge of thoracolumbar deformities, T-1 incidence and cervical sagittal balance can further our understanding of cervical deformities. Other important parameters that account for the cervical-pelvic relationship are surveyed in detail, and it is recognized that all such parameters need to be validated in studies that correlate HRQOL outcomes following cervical deformity correction.
\end{abstract}

(http://thejns.org/doi/abs/10.3171/2013.4.SPINE12838)

\section{KeY Words - cervical spine alignment - cervical deformity • cervical myelopathy $\quad$ - cervical adjacent-segment disease $\quad$ - sagittal vertical axis $\bullet$ health-related quality of life}

$\mathrm{O}$ VER the last decade, multiple publications have identified the important radiographic parameters in the thoracolumbar spine that have direct effects on HRQOL. Normative global and regional parameters

Abbreviations used in this paper: $\mathrm{ACDF}=$ anterior cervical discectomy and fusion; $\mathrm{ASD}=$ adjacent-segment disease; $\mathrm{CBVA}=$ chin-brow to vertical angle; $\mathrm{CSM}=$ cervical spondylotic myelopathy; $\mathrm{CTJ}=$ cervicothoracic junction; HRQOL $=$ health-related quality of life; NDI = Neck Disability Index; SF-36 = 36-Item ShortForm Health Survey; SVA = sagittal vertical axis. have been defined and critical thresholds for sagittal realignment planning have been established. However, relatively few publications have defined these normative values for cervical alignment, and even fewer have directly evaluated the influence of segmental, regional, and global balance on outcomes in cervical surgery.

The cervical spine is a remarkably complex segment,

This article contains some figures that are displayed in color online but in black-and-white in the print edition. 
as it not only supports the mass of the head but also allows the widest range of motion relative to the rest of the spine. The intricacies of the cervical region make it susceptible to a variety of disorders and complications, many of which inevitably lead to, or even begin with, alignment pathology that may warrant surgical consideration. Abnormalities of this critical segment can be debilitating and induce adverse effects on the overall functioning and HRQOL of the patient. Furthermore, the cervical spine plays a pivotal role in influencing subjacent global spinal alignment and pelvic tilt as compensatory changes occur to maintain horizontal gaze.

In the past, research conducted on the relationship between spinal malalignment and HRQOL has largely focused on the thoracolumbar and pelvic regions, and comparatively little attention has been given to the cervical spine. Currently, indications for surgery to correct cervical alignment are not well defined and there is no set standard to address the amount of correction to be achieved. Furthermore, classifications of cervical deformity have yet to be fully established and treatment options defined and clarified. Therefore, the purpose of this article is to provide a comprehensive review of cervical alignment parameters and related outcome measures that may provide guidance for proper surgical treatment and highlight deficiencies in the current literature. Comparisons to established spinal pelvic parameters that predict disability in thoracolumbar surgery will be described. Other pathologies that are closely influenced by cervical deformity, including ASD and myelopathy, are also discussed.

\section{Cervical Spine Alignment Parameters}

The cervical spine is primarily responsible for the location of the head over the body as well as the level of horizontal gaze. The center of mass of the head in the sagittal plane directly overlies the occipital condyle, approximately $1 \mathrm{~cm}$ above and anterior to the external auditory canal, ${ }^{7}$ and any deviations from the normal alignment of the mass of the head result in an increase in cantilever loads, which subsequently induces an increase in muscular energy expenditure. Cervical spine stability has been described by dividing the bone anatomy of the cervical spine into 3 primary columns (1 anterior and 2 posterior), which was first proposed by Louis ${ }^{67}$ and validated by Pal and Sherk. ${ }^{83}$ The anterior column consists of the vertebral bodies and discs while the 2 posterior columns consist of the articulating facet joints. ${ }^{67,83}$ This is in contrast to the Denis column classification of the thoracolumbar spine, which is composed of anterior, middle, and posterior columns. ${ }^{17}$ In this classification, the anterior column consists of the anterior longitudinal ligament, the anterior annulus fibrosis, and the anterior part of the vertebral body. ${ }^{17}$ The middle column consists of the posterior longitudinal ligament, posterior annulus fibrosis, and posterior half of the vertebral body. ${ }^{17}$ The posterior column consists of the posterior arch and the ligamentous complex. ${ }^{17}$ In the cervical spine, the weight of the head is born through the condyle to the lateral masses of C-1 and then to the $\mathrm{C} 1-2$ joint. This load is then divided via the $\mathrm{C}-2$ articular pillars to the anterior column (which includes the C2-3 disc) and the posterior column (which includes the $\mathrm{C} 2-3$ facets). ${ }^{83}$ The load distribution of the cervical spine is primarily in the posterior columns, with $36 \%$ in the anterior column and $64 \%$ in the 2 posterior columns. ${ }^{83}$ This is in contrast to the lumbar spine, in which the anterior loads $(67 \%-82 \%)$ have been reported as higher than the posterior loads (18\%-33\%). ${ }^{66,78}$ The natural curvature of the cervical spine maintains a lordotic shape ${ }^{26}$ as a result of the wedge-shaped cervical vertebrae and the need to compensate for the kyphotic curvature of the thoracic spine. ${ }^{26}$ This thoracic kyphosis permits expanded lung volumes in the normal range and has been shown to increase with age. The caudal end of the lordotic cervical spine joins the rigid kyphotic thoracic inlet at the CTJ. Deviations from this curvature, such as a loss of lordosis or the development of cervical kyphosis, are associated with pain and disability. 3,26,29,33,74,104

The 3 primary methods to assess cervical lordosis include Cobb angles, Jackson physiological stress lines, and the Harrison posterior tangent $\operatorname{method}^{34}$ (Fig. 1), the most common of which are Cobb angles typically measured from C-1 to C-7 or C-2 to C-7. The 4-line method includes drawing a line either parallel to the inferior endplate of C-2 or extending from the anterior tubercle of $\mathrm{C}-1$ to the posterior margin of the spinous process, and another line parallel to the inferior endplate of C-7. Perpendicular lines are then drawn from each of the 2 lines noted above and the angle subtended between the crossing of the perpendicular lines is the cervical curvature angle $^{34}$ (Fig. 1A). The Jackson physiological stress line method requires drawing 2 lines, both parallel to the posterior surface of the C-7 and C-2 vertebral bodies, and measuring the angle between them ${ }^{43}$ (Fig. 1B). Lastly, the Harrison posterior tangent method involves drawing lines parallel to the posterior surfaces of all cervical vertebral bodies from $\mathrm{C}-2$ to $\mathrm{C}-7$ and then summing the segmental angles for an overall cervical curvature angle ${ }^{34}$ (Fig. 1C). It has been suggested that the Cobb $\mathrm{C} 1-7$ angle overestimates cervical lordosis, that the Cobb C2-7 angle underestimates cervical lordosis, and that the Harrison method may provide the best estimate of lordosis. ${ }^{34}$ Despite this finding, the Cobb method remains the clinical mainstay of cervical lordosis measurement due to its ease of use, as well as its good intrarater and interrater reliability. ${ }^{87,98}$

Translation of the cervical spine in the sagittal plane is measured through the cervical SVA, for which there are different methods of measurement. Both C-2 SVA (Figs. 2 and 3 left) and C-7 SVA have been used to define sagittal alignment globally by measuring the distance between the C-2 and C-7 plumb lines, respectively, from the posterior superior corner of the sacrum. Cervical SVA can also be defined regionally using the distance between a plumb line dropped from the centroid of C-2 (or dens) and the posterosuperior aspect of C-7 (C2-7 SVA; Figs. 2 and 3) The gravity line measured from the center of gravity of the head has been proposed as an additional method to the C-7 plumb line to assess global sagittal alignment (center of gravity SVA; Fig. 3 left). 22,25,62,65,69,93,115 This method may also be applied regionally to cervical SVA using a plumb line drawn from the center of gravity of the head instead of C-2 (center of gravity to C-7 SVA). On lateral radiographs, 


\section{A review of cervical spine alignment}
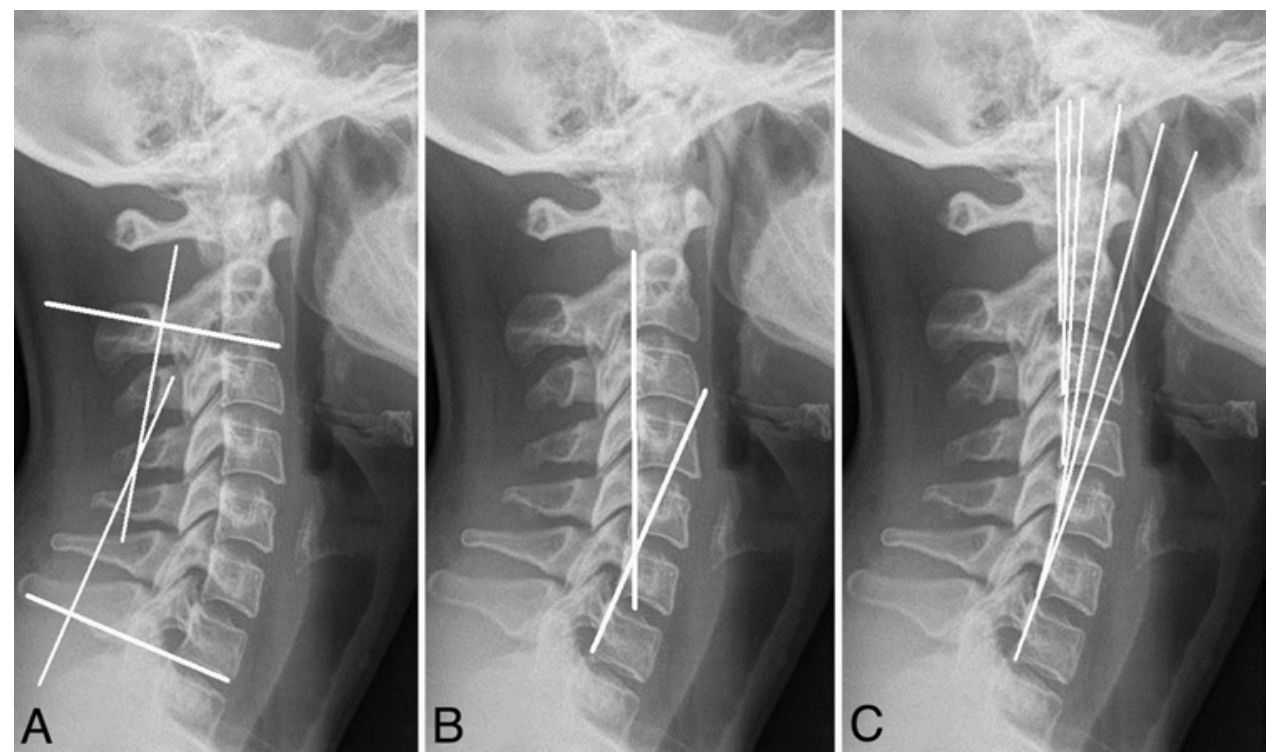

FIG. 1. Sagittal radiographs showing 3 different methods used to determine cervical lordosis. A: The 4-line method for measuring cervical $\mathrm{Cobb}$ angles. This method includes drawing a line either parallel to the inferior endplate of $\mathrm{C}-2$ or extending from the anterior tubercle of $\mathrm{C}-1$ to the posterior margin of the spinous process, and another line parallel to the inferior endplate of C-7. Perpendicular lines are then drawn from each of the 2 lines noted above, and the angle subtended between the crossing of the perpendicular lines is the cervical curvature angle. $\mathbf{B}$ : The Jackson physiological stress lines method for measuring cervical curvature. The method requires drawing 2 lines, both parallel to the posterior surface of the C-7 and C-2 vertebral bodies and measuring the angle between them. C: The Harrison method for measuring cervical curvature. The Harrison posterior tangent method involves drawing lines that are parallel to the posterior surfaces of all cervical vertebral bodies from C-2 to C-7 and then summing the segmental angles for an overall cervical curvature angle.

the center of gravity of the head can be approximated by using the anterior portion of the external auditory canal as the initial point for the plumb line ${ }^{7}$ (Fig. 3 left). However, the $\mathrm{C}-2$ plumb line is especially clinically relevant because it has been directly correlated with HRQOL, in which larger C-2 SVA relates to poorer HRQOL.104
The CBVA is an assessment of horizontal gaze. This measurement is especially useful in the management of severe, rigid, cervical kyphotic deformities, as the loss of horizontal gaze has a significant impact on activities of daily living and quality of life. ${ }^{102}$ The CBVA is defined as the angle subtended between a line drawn from the
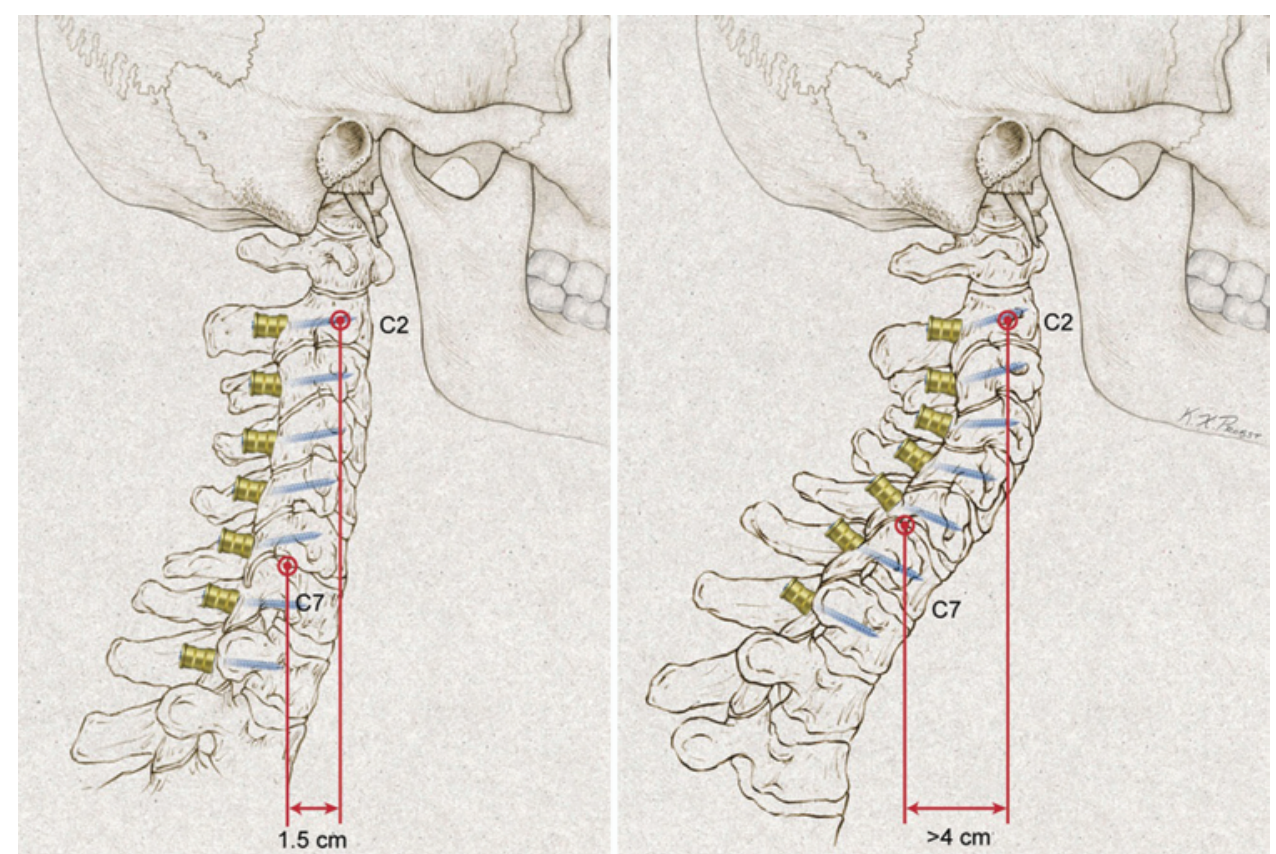

FIG. 2. Artist's drawings of normal cervical lordosis (left) highlighting a small distance $(1.5 \mathrm{~cm})$ between the C-2 and C-7 plumb lines and of cervical sagittal malalignment (right) highlighting a large distance ( $>4 \mathrm{~cm})$ between the C-2 and C-7 plumb lines. 

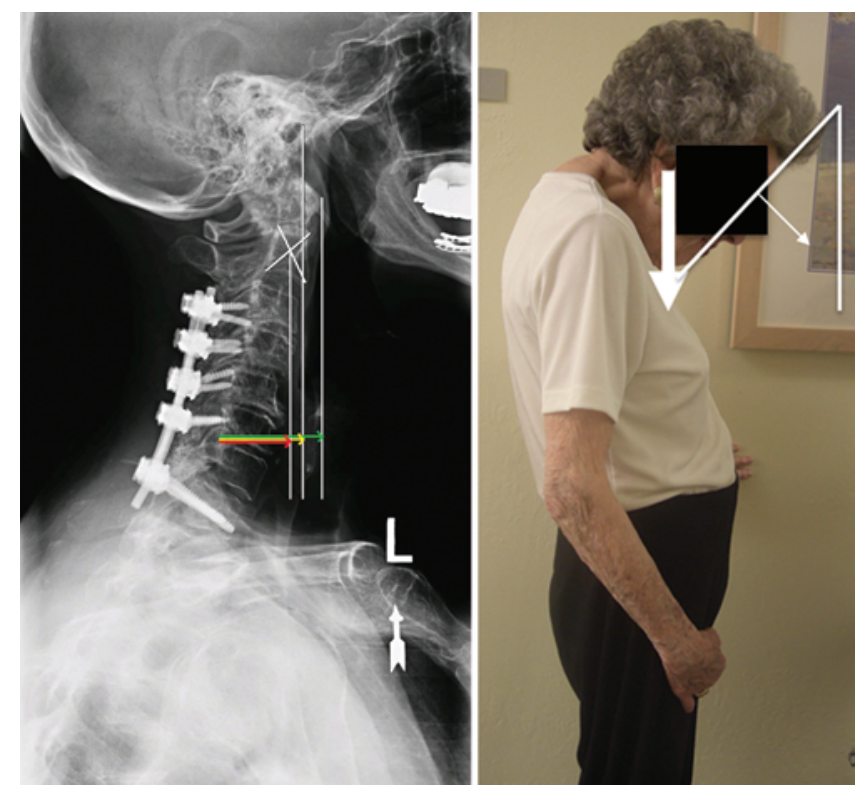

FIG. 3. Examples of the cervical SVA measurement (left) and the CBVA (right). Left: Visual representation of the technique used to measure cervical SVA. The green arrow represents C1-7 SVA (distance between a plumb line dropped from the anterior tubercle of $\mathrm{C}-1$ and posterior superior corner of C-7), the red arrow represents $\mathrm{C} 2-7$ SVA (distance between a plumb line dropped from the centroid of C-2 and posterior superior corner of C-7), and the yellow arrow represents center of gravity to C-7 SVA (distance between a plumb line dropped from the anterior margin of the external auditory canal and the posterior superior corner of C-7). Right: Representation of the CBVA measurement method portrayed on a clinical photograph of a patient standing with hips and knees extended while her neck is in a neutral or flexed position. The CBVA is defined as the angle subtended between a line drawn from the patient's chin to brow and a vertical line. Surgical correction of the CBVA requires extension of the cervical spine.

patient's chin to brow and a vertical line (Fig. 3 right). ${ }^{102}$ The angle is measured on clinical photographs of the patient standing with hips and knees extended while the neck is in a neutral or fixed position. ${ }^{102}$ This parameter is gaining popularity, and deformity correction that has considered CBVA has been shown to be associated with positive postoperative outcomes such as improved gaze, ambulation, and activities of daily living. .9,53,54,86,102,110 $^{2}$

Lee et al. ${ }^{64}$ introduced the concepts of thoracic inlet angle, neck tilt, cervical tilt, and cranial tilt, which have all been found to be related to cervical alignment (discussed below). The thoracic inlet angle was defined as the angle between a line originating from the center of the T-1 endplate and perpendicular to the T-1 endplate and a line from the center of the T-1 endplate and the upper end of the sternum. Neck tilt was defined as an angle between 2 lines both originating from the upper end of the sternum, with 1 being a vertical line and the other connecting to the center of the T-1 endplate. A relationship exists such that thoracic inlet angle equals $\mathrm{T}-1$ slope (angle between a horizontal plane and a line parallel to the superior T-1 endplate; Fig. 4) plus neck tilt. This is similar to the equation in the lumbar spine in which pelvic incidence equals the sacral slope plus the pelvic tilt. Cervical tilt was defined as the angle between 2 lines, both originating from the center of the T-1 upper endplate; one is perpendicular to the T-1 endplate

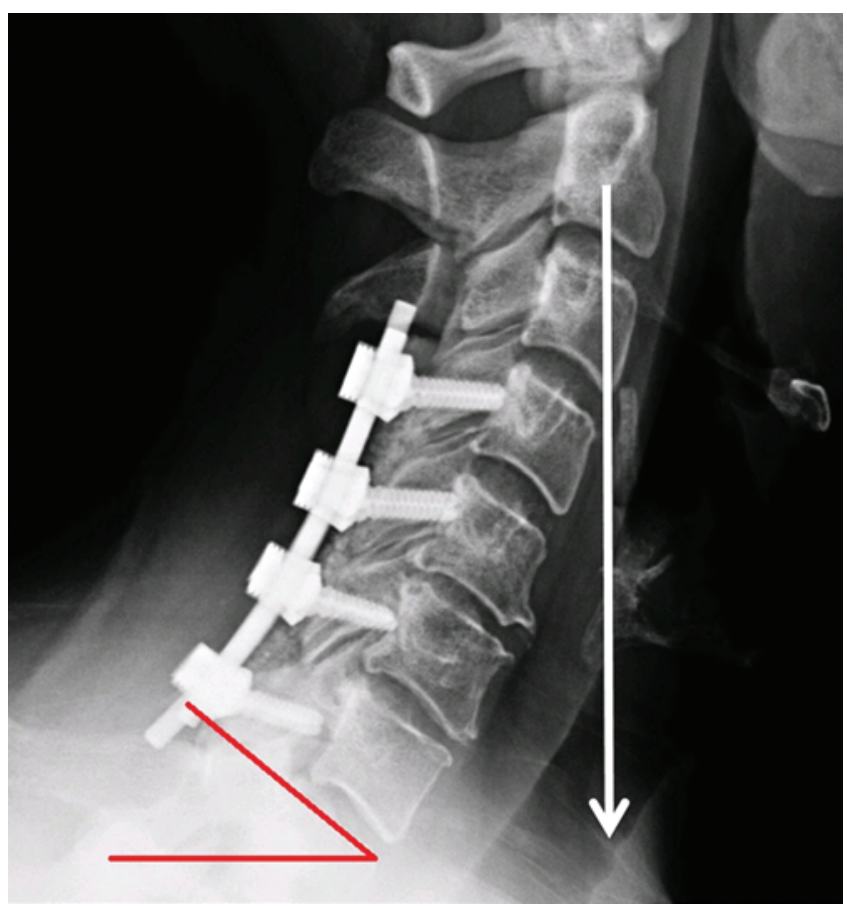

FIG. 4. Lateral radiograph demonstrating the angle of the T-1 slope and its relationship to cervical SVA.

and the other passes through the tip of the dens. Cranial tilt was defined as the angle between 2 lines, both originating from the center of the T-1 upper endplate, with 1 passing through the dens (same as the second line in cervical tilt) and the other being a vertical line.

\section{Normal Cervical Alignment}

Because the cervical spine is the most mobile part of the spinal column, a wide range of normal alignment has been described (Tables 1-4; Blondel B, Schwab F, and Ames CP, unpublished data, 2012). ${ }^{29,30,33}$ In asymptomatic normal volunteers a large percentage (approximately $75 \%-80 \%$ ) of cervical standing lordosis is localized to C1-2 $2^{33,44}$ and relatively little lordosis exists in the lower cervical levels. Similarly, most lumbar lordosis occurs at

TABLE 1: Normal segmental cervical angles in asymptomatic adults*

\begin{tabular}{lc}
\hline Level & \multicolumn{1}{c}{ Angle $\left(^{\circ}\right)$} \\
\hline C0-1 & $2.1 \pm 5.0$ \\
C1-2 & $-32.2 \pm 7.0$ \\
C2-3 & $-1.9 \pm 5.2$ \\
C3-4 & $-1.5 \pm 5.0$ \\
C4-5 & $-0.6 \pm 4.4$ \\
C5-6 & $-1.1 \pm 5.1$ \\
C6-7 & $-4.5 \pm 4.3$ \\
C2-7 & -9.6 \\
total (C1-7) & -41.8 \\
\hline
\end{tabular}

* Values presented as mean $\pm \mathrm{SD}$; negative sign indicates lordosis in the segmental values. Data from Hardacker et al., 1997. 
TABLE 2: Normal cervical SVA values in asymptomatic adults*

\begin{tabular}{cc}
\hline Odontoid Marker & Mean \pm SD $(\mathrm{mm})$ \\
\hline at C-7 & $15.6 \pm 11.2$ \\
at sacrum & $13.2 \pm 29.5$ \\
\hline
\end{tabular}

* Data from Hardacker et al., 1997.

the caudal end with L5-S1 having the largest segmental lordotic angle. ${ }^{9}$ That the preponderance of cervical lordosis is localized to $\mathrm{C} 1-2$ may be explained by the findings of Beier et al., ${ }^{7}$ who showed that the center of gravity of the head sits almost directly above the centers of the C-1 and $\mathrm{C}-2$ vertebral bodies. The mean total cervical lordosis is approximately $-40^{\circ}$, and on average the occiput- $\mathrm{Cl}$ segment is kyphotic..$^{33}$ Only $6^{\circ}(15 \%)$ of lordosis occurs at the lowest 3 cervical levels (C4-7). ${ }^{33}$ The loss of subaxial lordosis has been reported in occiput-C2 fusions in which excessive hyperlordosis is created at occiputC2. ${ }^{12,113}$ This type of unfavorable reciprocal change is also observed in lumbar and thoracic osteotomy and has been reported by Lafage et al. ${ }^{61}$ Furthermore, there is no difference between asymptomatic men and women in total cervical lordosis, and there is a positive correlation between cervical lordosis and increasing age. ${ }^{30,33}$ The average odontoid-C7 plumb line distance ranges from 15 to $17 \mathrm{~mm} \pm 11.2 \mathrm{~mm} .{ }^{33}$ Normal CBVA has not been characterized, but postoperative values of $+10^{\circ}$ to $-10^{\circ}$ have been well tolerated in patients..$^{19,53,54,86,102,110}$

Cervical lordosis may be dependent on the anatomy of the CTJ, which typically involves the C-7 and T-1 vertebrae, the $\mathrm{C} 1-7$ discs, and the associated ligaments, and may extend to T-2 and T-3 in terms of osteotomy planning. ${ }^{109}$ The CTJ also includes the thoracic inlet, a fixed bony circle that is composed of the T-1 vertebral body, the first ribs on both sides, and the upper part of the sternum. Biomechanically, the CTJ is a region in which the highly mobile cervical spine, which supports the head (average weight $4.5 \mathrm{~kg}$ ), ${ }^{111}$ transitions into the fairly rigid thoracic spine whose mobility is significantly reduced by the rib cage. Furthermore, the CTJ is the site at which lordosis of the cervical spine changes to kyphosis in the thoracic spine. This change in curvature causes a significant amount of stress at the CTJ, both in the static and dynamic states. ${ }^{4,109}$

The sagittal alignment of the cranium and cervical spine may be influenced by the shape and orientation of the thoracic inlet to maintain a balanced, upright posture

TABLE 3: Normal cervical lordosis values for men and women in different age groups in asymptomatic adults*

\begin{tabular}{ccc}
\hline Age Group & Men $\left(^{\circ}\right)$ & Women $\left(^{\circ}\right)$ \\
\hline $20-25$ & $16 \pm 16$ & $15 \pm 10$ \\
$30-35$ & $21 \pm 14$ & $16 \pm 16$ \\
$40-45$ & $27 \pm 14$ & $23 \pm 17$ \\
$50-55$ & $22 \pm 15$ & $25 \pm 11$ \\
$60-65$ & $22 \pm 13$ & $25 \pm 16$ \\
\hline
\end{tabular}

* Values presented as means \pm SDs. Data from Gore et al., 1986. and horizontal gaze, similar to the relationship between the pelvic incidence and lumbar lordosis (Fig. 5 upper and lower). ${ }^{64}$ Lee et al.${ }^{64}$ found significant correlations between the thoracic inlet angle and both the cranial offset and craniocervical alignment (Fig. 6). The relative contributions of the occiput-C2 angle and the C2-7 angle to overall cervical lordosis have been reported to be $77 \%$ and $23 \%$, respectively, in asymptomatic individuals. ${ }^{64}$ The relative contributions of cervical tilting and cranial tilting to the overall angle of the occipitocervical region have been reported to be $70 \%$ and $30 \%$, respectively, in asymptomatic individuals. ${ }^{64}$

In the study of Lee et al., ${ }^{64}$ neck tilting was maintained at approximately $44^{\circ}$ to minimize energy expenditure of the neck muscles. These results indicate that a small thoracic inlet angle creates a small T-1 slope and small cervical lordosis angle to maintain the physiological neck tilting, and vice versa. According to the study, the thoracic inlet angle and T-1 slope may be used as parameters to evaluate sagittal balance, predict physiological alignment, and guide deformity correction of the cervical spine. ${ }^{64}$ The T-1 inclination will determine the amount of subaxial lordosis required to maintain the center of gravity of the head in a balanced position, and it will vary depending on global spinal alignment as measured by SVA and by inherent upper thoracic kyphosis. In patients with scoliosis, the T-1 sagittal angle (tilt, Fig. 4) has been shown to correlate directly with SVA measured from the $\mathrm{C}-2$ dens plumb line to provide a measure of overall sagittal alignment ${ }^{58}$ (Figs. 4 and 5).

The spinal regions (the pelvis and the lumbar, thoracic, and cervical regions) are not independent of one another and multiple significant correlations have been found between them. Blondel at al. (unpublished data, 2012) investigated all spinal parameters in an asymptomatic volunteer population with a mean age of 45 years (range 20-77 years). Following an extensive analysis, the authors found that pelvic incidence correlates with lumbar lordosis, lumbar lordosis correlates with thoracic kyphosis, and thoracic kyphosis correlates with cervical lordosis (Fig. 7 upper; unpublished data, 2012). Thus, an increase in pelvic incidence correlates with an increase in lumbar lordosis, which correlates with an increase in thoracic kyphosis, which then correlates with an increase in cervical lordosis (unpublished data, 2012). However, there was a lack of correlation found between pelvic incidence and thoracic kyphosis, making the chain of correlation from the pelvis to the cervical spine more complicated. The current view is that lumbar lordosis is proportional to pelvic incidence and thoracic kyphosis because pelvic incidence is a fixed parameter and thoracic kyphosis has little flexibility. Patients with a small pelvic incidence or small thoracic kyphosis had smaller lumbar lordosis than patients with small pelvic incidence and large thoracic kyphosis. This demonstrates that thoracic kyphosis is not a result of lumbar lordosis, but rather lumbar lordosis is a result of thoracic kyphosis and pelvic incidence. As mentioned above, cervical lordosis was correlated with thoracic kyphosis, showing that as thoracic kyphosis increases, cervical lordosis also increases. However, this change in cervical lordosis is not large enough to main- 
J. K. Scheer et al.

TABLE 4: Mean sagittal parameters among the volunteers stratified by age group*

\begin{tabular}{|c|c|c|c|c|c|c|c|}
\hline \multirow[b]{2}{*}{ Variable } & \multicolumn{2}{|c|}{$20-39$ yrs } & \multicolumn{2}{|c|}{$40-59$ yrs } & \multicolumn{2}{|c|}{$>60 \mathrm{yrs}$} & \multirow[b]{2}{*}{$\mathrm{p}$ Value $†$} \\
\hline & Mean & SD & Mean & SD & Mean & SD & \\
\hline C2-7 cervical lordosis $\left(^{\circ}\right)$ & +9.4 & 9 & +6.6 & 9 & +22.2 & 9 & $<0.001$ \\
\hline T4-12 thoracic kyphosis $\left({ }^{\circ}\right)$ & -38.1 & 11 & -36 & 9 & -45 & 14 & NS \\
\hline L1-S1 lumbar lordosis $\left(^{\circ}\right)$ & +61.5 & 12 & +60.3 & 7 & +55.7 & 13 & NS \\
\hline pelvic tilt $\left(^{\circ}\right)$ & 12.1 & 7 & 14.5 & 5 & 15.1 & 8 & NS \\
\hline pelvic incidence $\left({ }^{\circ}\right)$ & 52.1 & 10 & 54.3 & 8 & 53.5 & 10 & NS \\
\hline sacral slope $\left({ }^{\circ}\right)$ & 40 & 9 & 39.9 & 7 & 36.5 & 10 & NS \\
\hline SVA (mm) & -28.5 & 28 & -18.2 & 39 & +22.4 & 40 & $<0.001$ \\
\hline T-1 slope $\left(^{\circ}\right)$ & -22 & 7 & -21.1 & 8 & -31.6 & 9 & 0.001 \\
\hline
\end{tabular}

* Unpublished data, Blondel et al., 2012. NS = nonsignificant.

$\dagger \mathrm{p}$ values refer to ANOVA comparison between groups.

tain the head over the pelvis, but it does provide adequate maintenance of horizontal gaze. In addition to the correlations between cervical lordosis and thoracic kyphosis, cervical lordosis was also found to correlate with SVA, pelvic tilt (Fig. 7 lower), and T-1 slope (unpublished data, 2012). Subjects who had a positive SVA demonstrated an increase in cervical lordosis, regardless of whether their SVA was within the normal range of values. This cervical adaptation to sagittal global alignment is a compensatory mechanism to maintain a horizontal gaze as mentioned above. Therefore, cervical lordosis can be considered, similar to thoracic kyphosis and lumbar lordosis, as an adaptive spinal segment to global alignment. When lumbar lordosis and thoracic kyphosis are adapted to the patient's pelvic incidence, the amount of cervical lordosis will be proportional to the other curves. However, when the patient has an anterior malalignment of the spine (from a reduction in lumbar lordosis and/or increase in thoracic kyphosis) an increase in cervical lordosis is a compensatory mechanism. Conversely, if a primary cervical deformity exists, changes in the lumbar spine and pelvis will attempt to compensate, which is represented in Case 1 (Fig. 8).

The cervical alignment parameters discussed are critical in the evaluation and surgical planning for cervical deformity correction. Therefore, CBVA, cervical SVA (C-2 SVA) and regional cervical lordosis should all be considered in preoperative planning strategies, and consideration should be given to obtaining preoperative 3-foot standing radiographs that provide visualization from the external auditory canal (approximation of head center of mass) to the femoral heads.

\section{Cervical Deformity}

While deformity of the cervical spine occurs in both the sagittal and coronal planes, sagittal plane deformities not only arise more frequently, ${ }^{16,76,101}$ but when surgically corrected appear to play a more critical role in achieving better clinical outcomes. ${ }^{27}$ Deformity of the cervical spine can be categorized as either primary or secondary. Primary deformities are often congenital, while many secondary cervical deformities in the sagittal plane arise from iatrogenic causes or ankylosing spondylitis, $8,35,63,75,114$ a condition characterized by the ossification of the joints and ligaments in the spine. Left untreated, primary deformities in one region of the spine can lead to secondary deformities in another because the entire spine functions as 1 global unit whose individual regions can have a significant effect on each other. For example, a primary congenital lumbar hemivertebra can induce secondary cervical scoliosis (Fig. 9).

Cervical kyphosis is by far the most prevalent cervical spine deformity and commonly presents with iatrogenic origins, such as postlaminectomy kyphosis. ${ }^{2,15,18,49,82,101}$ Once the onset of cervical kyphosis begins, the deformity tends to perpetuate itself, with forward shifting of the head and neck inducing abnormal forces that lead to further progression of the deformity. The spinal cord may be compressed as it extends over the profile of the deformity, which may lead to a myriad of incapacitating symptoms, including myelopathy, loss of horizontal gaze, and

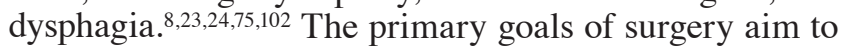
correct and stabilize the deformity while decompressing neural elements and restoring sagittal alignment.

It is important to appreciate that cervical sagittal alignment (cervical SVA) is closely related to the cervical sagittal Cobb angle (the C2-7 Cobb angle) as described above; however, cervical sagittal alignment also takes into account the alignment of subjacent segments, including the thoracolumbar spine and pelvis (Figs. 7 and 10). Deformities localized to the cervical spine affect, and are affected by, other parameters of the spine in preserving global sagittal alignment. Sagittal alignment factors into maintenance of posture, and patients with poor sagittal alignment often develop potentially painful compensatory mechanisms that affect the cervical spine, including hyperlordosis of subaxial segments ${ }^{10,11,55,68,99}$ (Fig. 11).

The main objectives of cervical deformity surgery include the maintenance/restoration of horizontal gaze, decompression of neural elements, and an overall effort to reestablish the normative alignment of the cervical spine. The most common radiographic parameters used in preoperative planning and postoperative assessment include regional measurements such as Cobb angles for kyphosis, C1-2 lordosis, and C2-7 lordosis. ${ }^{13,30,31,33,38,74}$ 

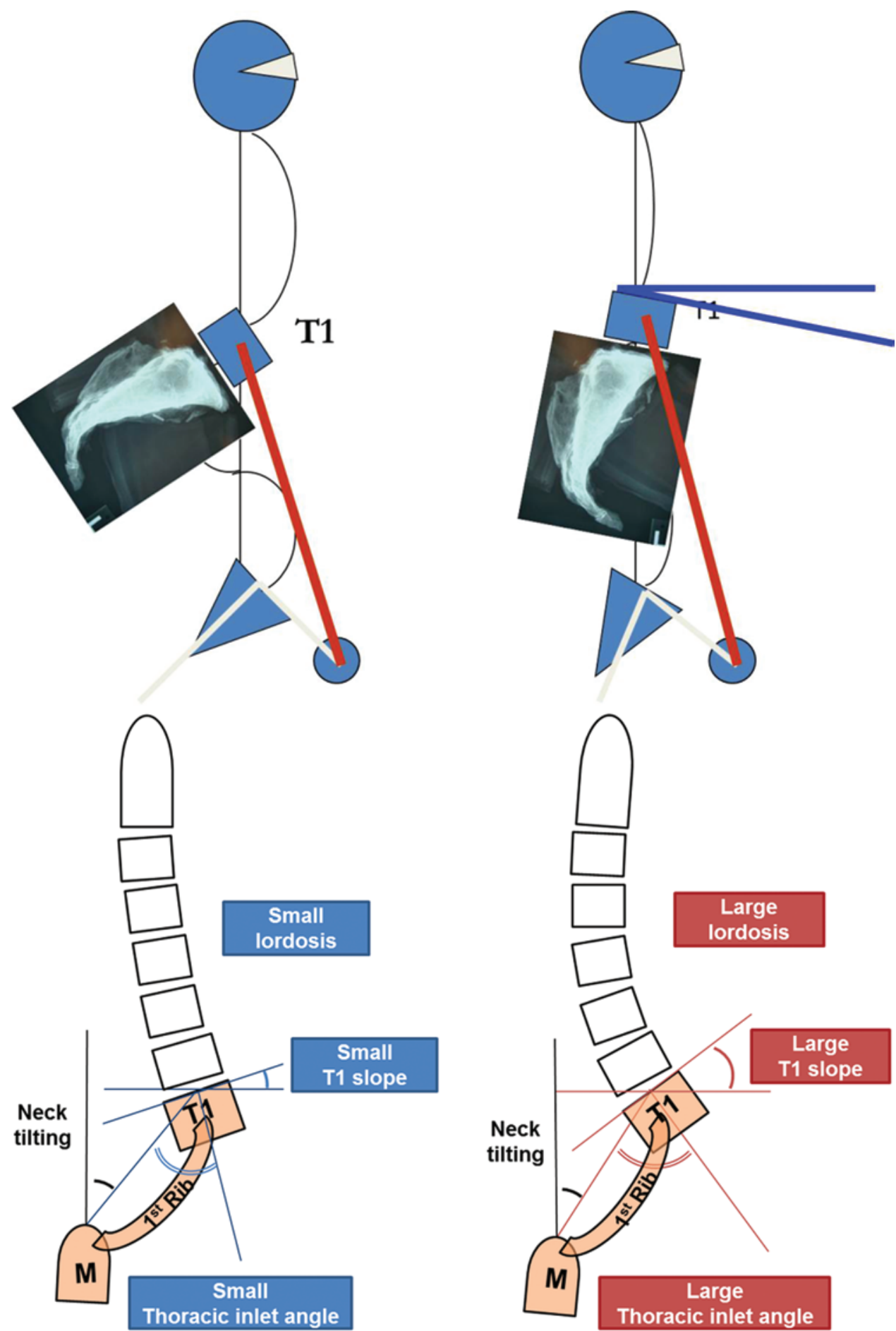

Fig. 5. Illustrations demonstrating the concept of T-1 slope and its effect on cervical lordosis (left), and the relationship between thoracic inlet angle, T-1 slope, and cervical lordosis (right). Upper: The relationship between T-1 slope and cervical lordosis is similar to the relationship between pelvic incidence and lumbar lordosis. A greater T-1 slope yields a greater magnitude of cervical lordosis just as a greater pelvic incidence leads to greater lumbar lordosis. Lower: A small thoracic inlet angle yields a low T-1 slope and therefore less cervical lordosis is required to balance the head over the thoracic inlet and trunk. Conversely, a large thoracic inlet angle yields a greater T-1 slope so that a greater magnitude of cervical lordosis is required to balance the head over the thoracic inlet and trunk. M = manubrium. Reproduced with permission from Lee et al.: J Spinal Disord Tech 25:E41-E47, 2012.64

Although the current literature reports changes in radiographic parameters of lordosis and kyphosis, ${ }^{1,8,77,80,114}$ there is no clear indication of an optimal amount of cervical lordosis to be achieved postoperatively, and it has become an accepted general rule to correct cervical kyphosis to be as close to neutral as possible. ${ }^{101}$ Current research is adopting a trend toward defining cervical sagittal alignment parameters similar to the accepted C-7 


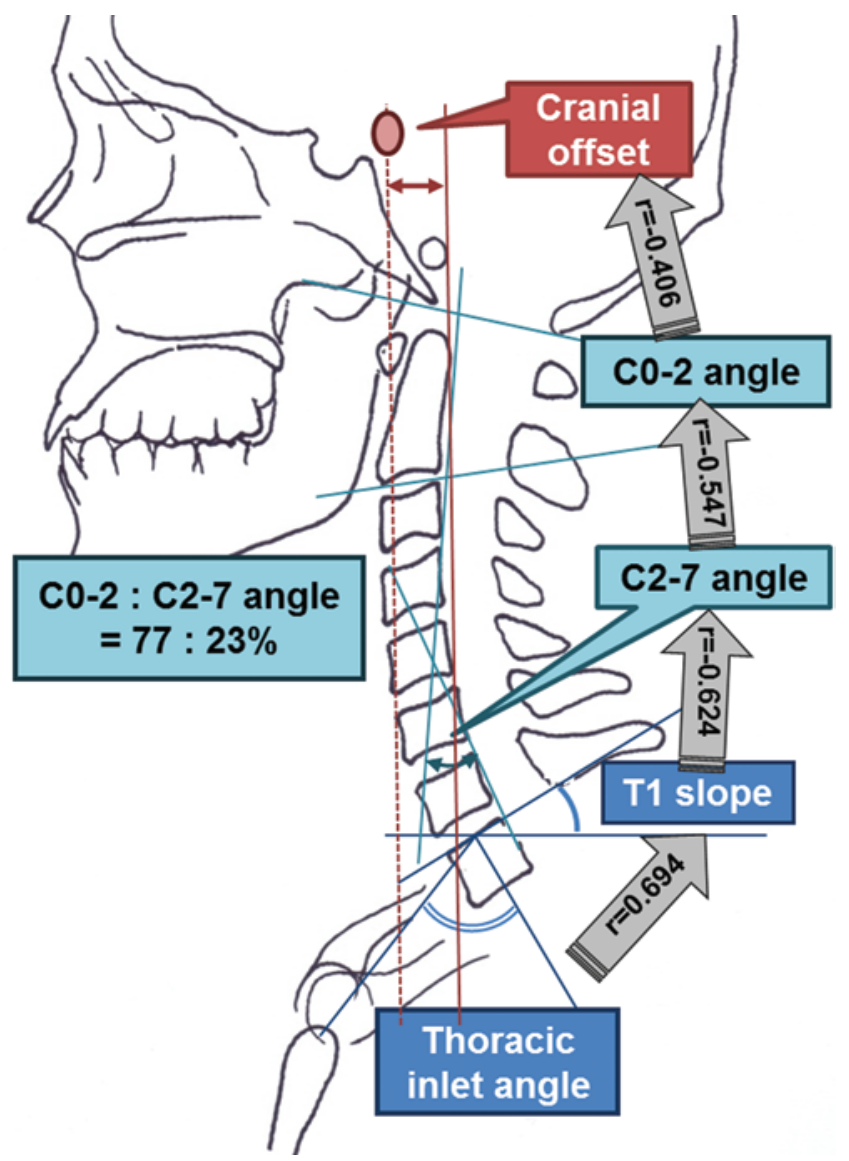

FIG. 6. Schematic drawing illustrating the sequential linkage of significant correlations from the thoracic inlet angle to the cranial offset and craniocervical alignment. The $r$ values within the arrows between the segments illustrate the Pearson correlation coefficient between the 2 segments. The sequential correlations between adjacent segments link the correlation between the thoracic inlet angle and the cranial offset. CO $=$ occiput. Adapted from Lee et al.: J Spinal Disord Tech 25:E41E47, 2012.64

SVA traditionally used to measure sagittal alignment of the thoracolumbar spine. ${ }^{107}$ Specifically, as noted above, the $\mathrm{C}-2$ plumb line and CBVA are increasingly being used. ${ }^{33,40,63,102,104}$ To evaluate the effect of cervical alignment in relation to the overall sagittal alignment of the spine, these measurements are based on standing 3-foot spine radiographs.

Few studies, however, report the relationship between radiographic parameters in the cervical spine and HRQOL. ${ }^{104}$ The effects of these cervical radiographic measurements on outcome scores are not nearly as welldefined as global and pelvic parameters are in thoracolumbar deformity. ${ }^{12,28,92,94}$ Furthermore, many of these studies neglect consideration of preoperative measurements that provide baseline values with which to compare postoperative status.

Of the few studies that explore associations between radiographs and clinical outcomes, there appears to be evidence suggesting that correlations between the two may be worth further investigation with larger sample sizes and more controlled prospective analyses. Among the outcome scores most frequently collected for the cer- vical spine are the NDI, SF-36 mental and physical component scores, and visual analog scale for neck pain as measures of clinical status, and Nurick grades, modified Japanese Orthopaedic Association scores, Odom scale scores, Frankel grades, and Ishihara indices as measures of functional status.

The majority of available reports provide assessment of regional measurements of kyphosis. A recurrent finding is the increase in complaints of neck pain in patients with greater kyphosis measurements, whether following cervical spine trauma ${ }^{48}$ or operative procedures such as anterior cervical spine fusion ${ }^{51}$ or single-level ACDF. ${ }^{60}$ Naderi et al. ${ }^{79}$ concluded that the presence of abnormal cervical curvature predicts less postoperative neurological improvement.

More recent works studying cervical alignment parameters (most represented as lordosis between C-2 and $\mathrm{C}-7)$ in relation to postoperative clinical outcomes are weak in suggesting significant correlations. Jagganathan et al. $^{45}$ found no significant relationship between the change in segmental kyphosis and postoperative functional status. Villavicencio et al. ${ }^{108}$ conducted a prospective, double-blind, randomized study evaluating the relationship between lordotic alignment (both cervical and segmental) and clinical outcomes using normal and lordotically shaped allografts for ACDF. They found that improved cervical Cobb angle alignment did not correlate significantly with clinical outcomes, but that maintaining or improving segmental sagittal alignment had significant implications for a higher degree of improvement in outcome scores. Similarly, Guérin et al. ${ }^{32}$ also noted that only segmental sagittal alignment correlated with clinical outcomes after cervical disc arthroplasty, while overall cervical lordotic alignment did not. The CBVA, while recognized to be the most objective measure of horizontal gaze, had no significant correlation with overall clinical outcome (the Modified Arthritis Impact Measurement Scale) in cervical kyphosis with ankylosing spondylitis. ${ }^{102}$ However, it has proven to be a very reliable and useful tool in assessing preoperative and postoperative horizontal gaze, and correction of the CBVA does lead to positive postoperative outcomes regarding a patient's satisfaction of horizontal gaze improvement. ${ }^{19,53,54,86,102,110}$

Interestingly, these studies investigating cervical alignment parameters primarily measure lordosis between C-2 and C-7 and not the aforementioned SVA parameters, with the exception of 1 study. ${ }^{104}$ Sagittal vertical axis values, however, are standard measurements taken to assess deformity in the thoracolumbar spine. In fact, both Glassman et al. ${ }^{27}$ and Mac-Thiong et al. ${ }^{69}$ concluded that positive sagittal malalignment, defined as a C-7 plumb line greater than $50 \mathrm{~mm}$ anterior to the posterosuperior aspect of the sacrum, is associated with a deterioration of quality of life in patients with adult spinal deformity. Mac-Thiong et al. ${ }^{69}$ even extended this association to involve the global balance as defined by the gravity line. Currently, only 1 study has broadened these observations between SVA measurements and HRQOL scores to include the cervical spine. The study by Tang et al. suggests that increasing cervical SVA is a cause for clinical concern of cervical malalignment indicated by poor HRQOL 

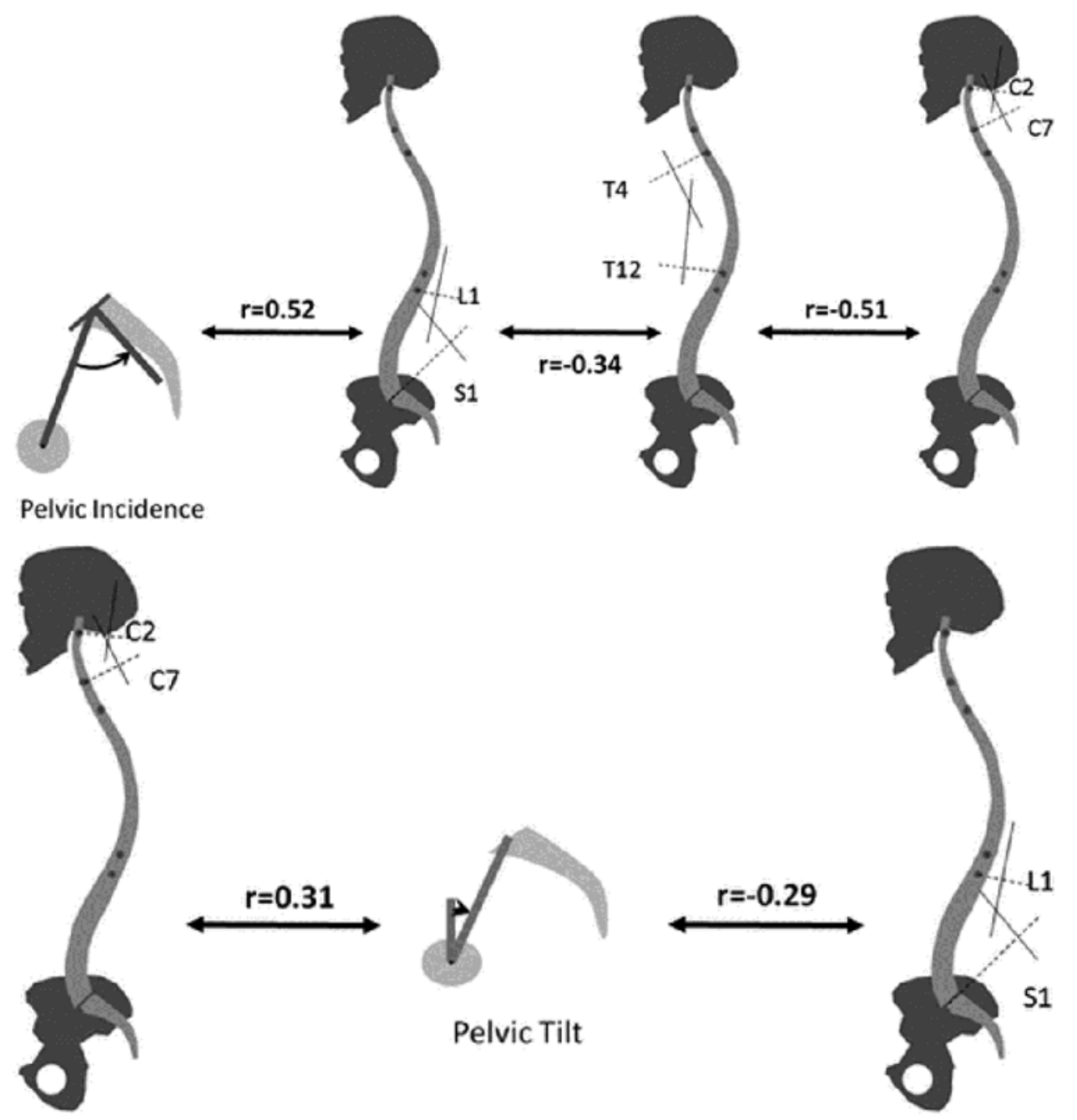

FIG. 7. Upper: Chain of correlation between pelvic incidence and regional sagittal parameters with the corresponding Pearson coefficient ( $r$ ) values. A large pelvic incidence requires a large lumbar lordosis $(r=0.52)$. An increase of lumbar lordosis is correlated with an increased thoracic kyphosis $(r=-0.34)$, which is correlated with an increased cervical lordosis $(r=-0.51)$. Lower: Correlation between pelvic tilt and lumbar/cervical lordosis. A loss of lumbar lordosis is correlated with a pelvic retroversion acting as compensatory mechanisms $(r=-0.29)$. Pelvic retroversion is also correlated with an increased cervical lordosis $(r=0.31)$. Blondel et al., unpublished data, 2012.

scores, and cervical SVA greater than $4 \mathrm{~cm}$ is correlated with worse outcomes assessed by the NDI (Fig. 12). ${ }^{104}$ In addition, the authors found significant correlations ( $\mathrm{p}$ $<0.0001)$ between the T-1 slope and $\mathrm{C} 2-7$ lordosis $(\mathrm{r}=$ $0.38)$, T-1 slope and C2-7 SVA ( $\mathrm{r}=0.44)$, as well as $\mathrm{C} 2-7$ SVA and the difference between the T-1 slope and $\mathrm{C} 2-7$ lordosis ( $\mathrm{T}-1$ slope $-\mathrm{C} 2-7$ lordosis, $\mathrm{r}=0.45$ ).

Even with the progressive findings linking radiographic parameters and clinical outcomes, limitations still exist in the study designs, as most are retrospective analyses. Especially overlooked in many of these studies is the contribution of the overall improvement in postoperative status that may be attributed to spinal cord decompression in many of these procedures. There is a clear need for future prospective studies to further isolate the effect of cervical alignment on outcome measures and eliminate confounding variables. Analysis of the cervical regional alignment with respect to overall spinal pelvic alignment will be critical.

\section{Cervical Deformity and ASD}

Adjacent-segment disease of the cervical spine is among the most controversial topics in spine surgery. Adjacent-segment disease has been defined as the development of new radiculopathy or myelopathy of a motion segment adjacent to the site of a previous arthrodesis of the spine (either superior or inferior). ${ }^{37,42,52,91,96,100}$ Because this is a clinical definition, it is often confused with a radiographic definition of adjacent segment degeneration in which disc degeneration is observed at adjacent motion segments to the fusion sites. However, studies have not demonstrated a clear correlation between the radiographic changes of adjacent segment degeneration and the clinical presentation of ASD..$^{6,36,37}$ Nevertheless, the two terms are used interchangeably to describe the phenomenon. The most current data suggest the prevalence of ASD ranges from $9 \%$ to $17 \%$ with an annual incidence ranging from $1.5 \%$ to $4 \%$ of the patients undergoing $\mathrm{ACDF}^{37}$ 


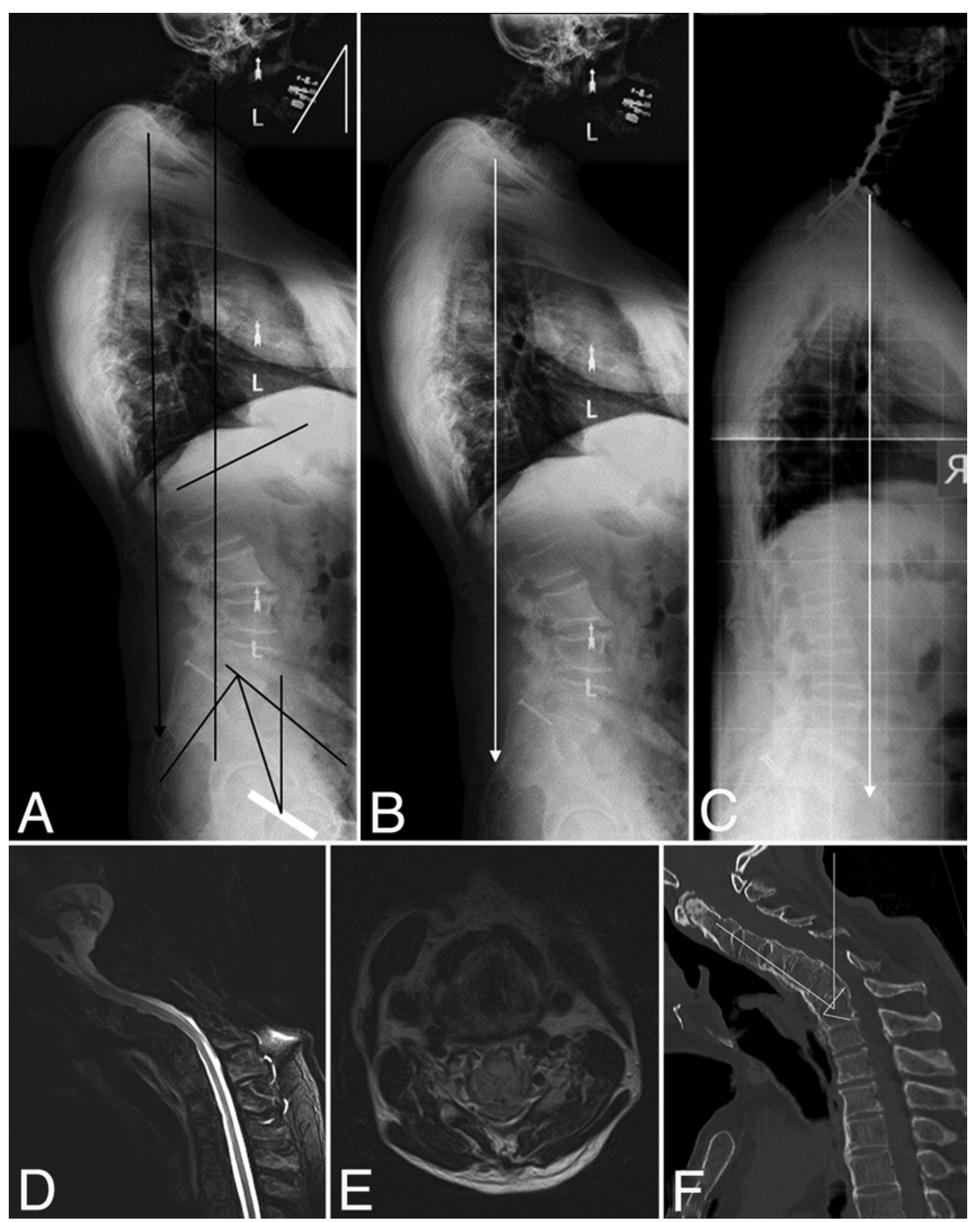

FIG. 8. Case 1. An example of cervical kyphosis resulting in lumbar hyperlordosis and negative global balance. A-C: Full standing 3-foot lateral radiograph (A) of a patient with a C-7 SVA of $-4.5 \mathrm{~cm}$, CBVA of $35^{\circ}, \mathrm{C} 2-7$ SVA of $6 \mathrm{~cm}$, pelvic incidence of $50^{\circ}$, lumbar lordosis of $72^{\circ}$, pelvic tilt of $22^{\circ}$, and pelvic incidence-lumbar lordosis of $-22^{\circ}$. Preoperative (B) and postoperative (C) lateral 3-foot standing radiographs demonstrate how correction leads to normalization of lumbar alignment and shifting of SVA to a positive position as lumbar spine alignment normalizes postoperatively. D-F: Sagittal (D) and axial (E) MR images demonstrate significant preoperative myelopathy. Sagittal CT scan (F) shows the preoperative T-1 slope (wedge shape) and the angle of the cervical spine related to the vertical.

There is overwhelming evidence for the existence of both clinical ASD and radiographic adjacent segment degeneration, but controversy remains about the origin of the ASD or degeneration. . $^{37,47,71,91,96,100}$ Investigations of whether ASD is the natural course of the spine or if adjacent spinal fusion contributes directly to ASD are still being conducted in hopes of finding a solid explanation. However, biomechanical studies have shown results of possible mechanisms of ASD. Despite the controversy over the origin of ASD, these studies all surround the idea that motion segments adjacent to cervical arthrodesis may result in increased loading and excessive motion 

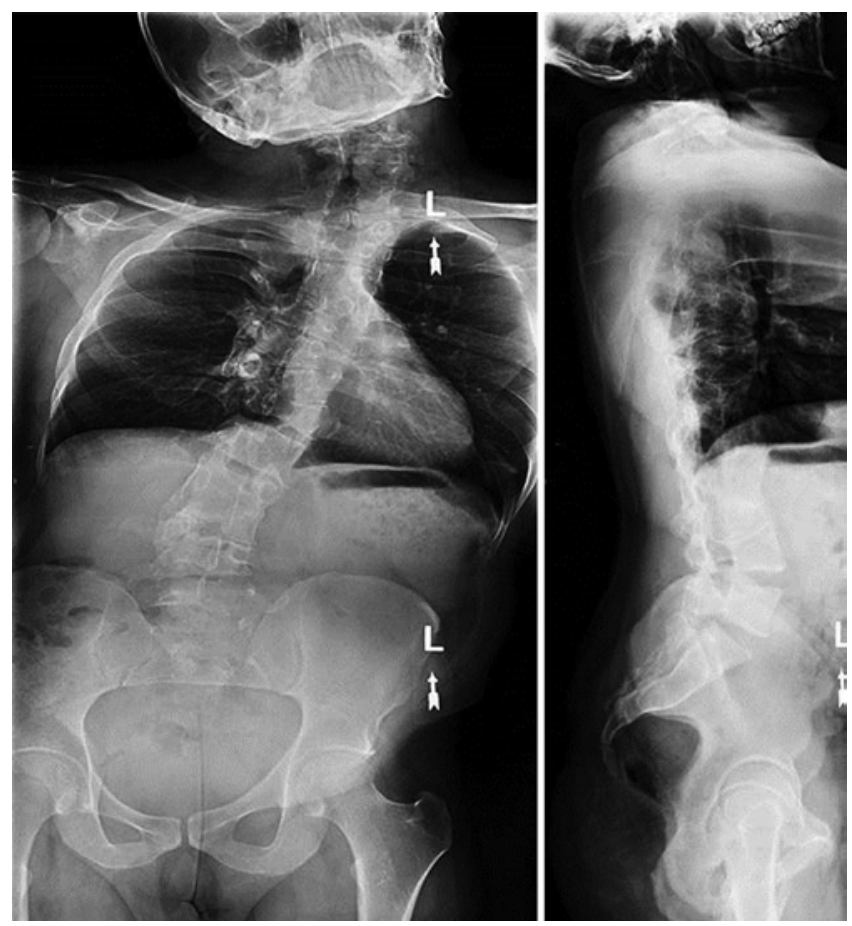

Fig. 9. Standing 3-foot radiographs showing an example of cervical scoliosis secondary to a lumbar hemivertebra.

leading to disc degeneration. ${ }^{21,70,72,84,88,89,95}$ The increased mechanical stress has been shown to interfere with the nutritional supply of the disc contributing to disc degeneration..$^{91}$ The discs rely on diffusion of nutrients into the disc due to the lack of blood supply, and an increased pressure within the disc may interfere with this diffusion process. Furthermore, increased mechanical loads on the disc are known to alter the extracellular matrix composition. ${ }^{39}$ These changes also occur with the normal aging process. ${ }^{14}$ The nutrition of the discs becomes impaired as calcification of the endplates and a reduction in peripheral arteries cause a lack of nutrition delivery as a person ages..$^{15}$ There is also a loss of cells and extracellular matrix with normal aging. ${ }^{14,39}$ Usually elderly patients are undergoing cervical arthrodesis and the normal degeneration process may confound the effect of ASD from the fusion, leading to the current controversy.

A much less studied topic is the relationship between cervical deformity and ASD, but it deserves significant attention. As discussed above, the cervical spine maintains a natural lordotic curvature. This curve allows the cervical spine to distribute the load of the head through the posterior columns (articular processes and facet joints) withstanding about $64 \%$ of the load and $36 \%$ for the anterior column. ${ }^{83}$ Therefore, it follows that kyphotic deformity of the cervical spine tends to shift the greater part of the load from the posterior columns to the anterior column. This could potentially increase adjacent segment mechanical load as discussed above and contribute to the development of ASD. There are a few studies that have examined this concept in the lumbar spine, with each one suggesting that postoperative sagittal malalignment of the lumbar spine and pelvis may promote ASD with a 4-fold increased incidence. ${ }^{20,59,85,90}$ An in vivo animal biomechanical study by Oda et al. ${ }^{81}$ demonstrated that postoperative lumbar kyphotic segments are forced into a hyperlordotic state creating a lordotic contracture, which leads to degenerative changes in the facet joints above and below the levels of fusion. Thus, correcting the sagittal alignment may reduce the development of ASD in the future. At the time of this review, to the best of our knowledge, there appears to be only 1 study investigating postoperative cervical kyphosis and ASD. Katsuura et al. ${ }^{50}$ performed a retrospective radiographic analysis of 42 patients who underwent ACDF with a minimum 5 -year follow up. They found that postoperative kyphosis of the cervical spine may contribute to the development of ASD. ${ }^{50}$ Of the 42 patients, $21(50 \%)$ had radiographic evidence of ASD. Of the normal group (without ASD), physiological cervical lordosis was preserved in 18 cases $(85.7 \%){ }^{50}$ However, normal physiological lordosis was only present in 9 cases $(42.8 \%)$ in the group with adjacent-level degeneration, which was significantly different compared with the normal group. ${ }^{50}$ Despite the small sample size of this study, the results suggest that cervical malalignment may contribute to ASD and this study lays the ground work for the initial investigation of this complicated topic. Further clinical studies with large sample sizes are needed to explore the relationship of cervical malalignment and the development of ASD.

\section{Cervical Deformity and Myelopathy}

Cervical spondylotic myelopathy is the most common cause of spinal cord dysfunction in patients more than 55 years old. ${ }^{57}$ The onset of CSM is generally insidious and involves a wide range of signs and symptoms depending on the cervical levels involved and the degree of neural compression. However, motor and sensory dysfunction are the most common complaints, with the legs often affected first. ${ }^{57,105}$ The origin of CSM has traditionally been described as a result of multilevel spondylosis in which degenerative changes in the discs lead to osteophyte formation. ${ }^{105}$ The osteophytes, along with ligamentous and facet hypertrophy, contribute to cervical spinal stenosis and eventually compress the spinal cord. ${ }^{105}$ Long-term stenosis and compression may cause demyelination and eventual necrosis of gray and white matter. ${ }^{73}$

Progressive cervical kyphosis has also been associated with myelopathy. The deformity leads to draping of the spinal cord against the vertebral bodies and anterior pathology, increasing the longitudinal cord tension due to the cord being tethered by the dentate ligaments and cervical nerve roots ${ }^{2,18}$ (Fig. 13). As the curve becomes more pronounced over time, the spinal cord becomes compressed and flattened. ${ }^{97}$ The anterior and posterior margins of the cord compress while the lateral margins expand. Tethering of the cord can produce increased intramedullary pressure. ${ }^{41,46,103}$ This compression leads to neuronal loss and demyelination of the cord.$^{97}$ Furthermore, there are significant adverse angiogenic effects of the mechanical compression. The small feeder blood vessels on the cord become flattened, leading to reduced blood supply. There is a large reduction in the number of vessels and the network size, as well as interruption and abnormal arrangement of 

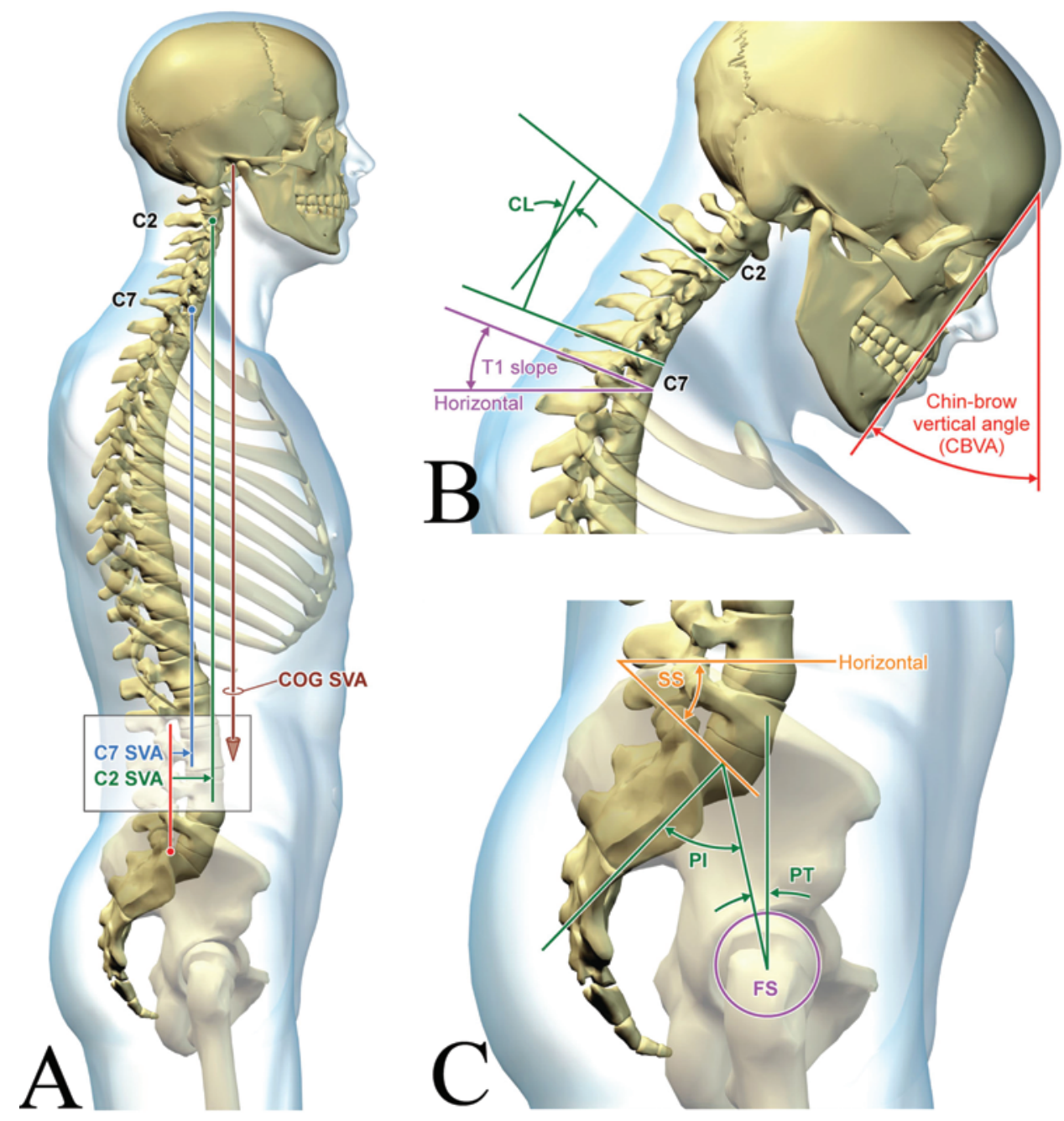

FIG. 10. The spine functions as a global unit so that cervical alignment parameters influence, and are influenced by, parameters in the lower regions. $\mathrm{CL}=$ cervical lordosis, $\mathrm{COG}=$ center of gravity, $\mathrm{FS}=$ femoral shaft, $\mathrm{PI}=$ pelvic incidence, $\mathrm{PT}=$ pelvic tilt. SS = sacral slope.

the blood vessels. ${ }^{97}$ As the kyphotic angle increases, these changes become greater, especially on the anterior side that is exposed directly to the mechanical compression. ${ }^{97}$ Greater cord tension increases intramedullary cord pressure $41,46,56,103$ and has been shown to lead to apoptosis in animal models. ${ }^{97}$ Shimizu et al. ${ }^{97}$ induced cervical kyphosis in small game fowls and quantitatively analyzed the severity of demyelination and neuronal loss in histological sections of the spinal cords. They found a significant correlation between the degree of kyphosis and the amount of cord flattening. ${ }^{97}$ Moreover, demyelination of the anterior fasciculus as well as neuronal loss and atrophy of the anterior horn was observed, with the extent of demyelination progressing as the kyphosis became greater ${ }^{97}$ The pattern of demyelination began with the anterior fasciculus but then progressed to the lateral and posterior fasciculi. ${ }^{97}$ Further analysis with angiography demonstrated that the vascular supply to the anterior portion of the cords was decreased. ${ }^{97}$ Thus, sagittal alignment of the cervical spine may play a substantial role in the development of cervical myelopathy, which is illustrated in Case 2 (Fig. 14).
The current literature is filled with controversy surrounding the best surgical approach to correct CSM..$^{57}$ Surgical considerations and options for treating cervical myelopathy must take into account the sagittal alignment of the cervical spine as it affects the approach as well as myelopathy origin and progression. Decompression alone, even ventral decompression, which does not decrease cord tension induced by kyphosis, may therefore not result in optimal outcomes. ${ }^{97}$

When correcting cervical myelopathy without sagittal malalignment, the surgeon should consider the possible future development of postlaminectomy kyphosis, which is the most common cause of cervical spine deformity. ${ }^{2,18,106}$ As mentioned above, the natural biomechanics of the spine rely on a lordotic curve to distribute most of the load posteriorly. Thus, the posterior neural arch is responsible for most of the load transmission down the cervical spine and removal of it causes a significant loss of stability. Initially, performing extensive multilevel laminectomies may not immediately destabilize an intact spine. However, the added instability with losing the pos- 


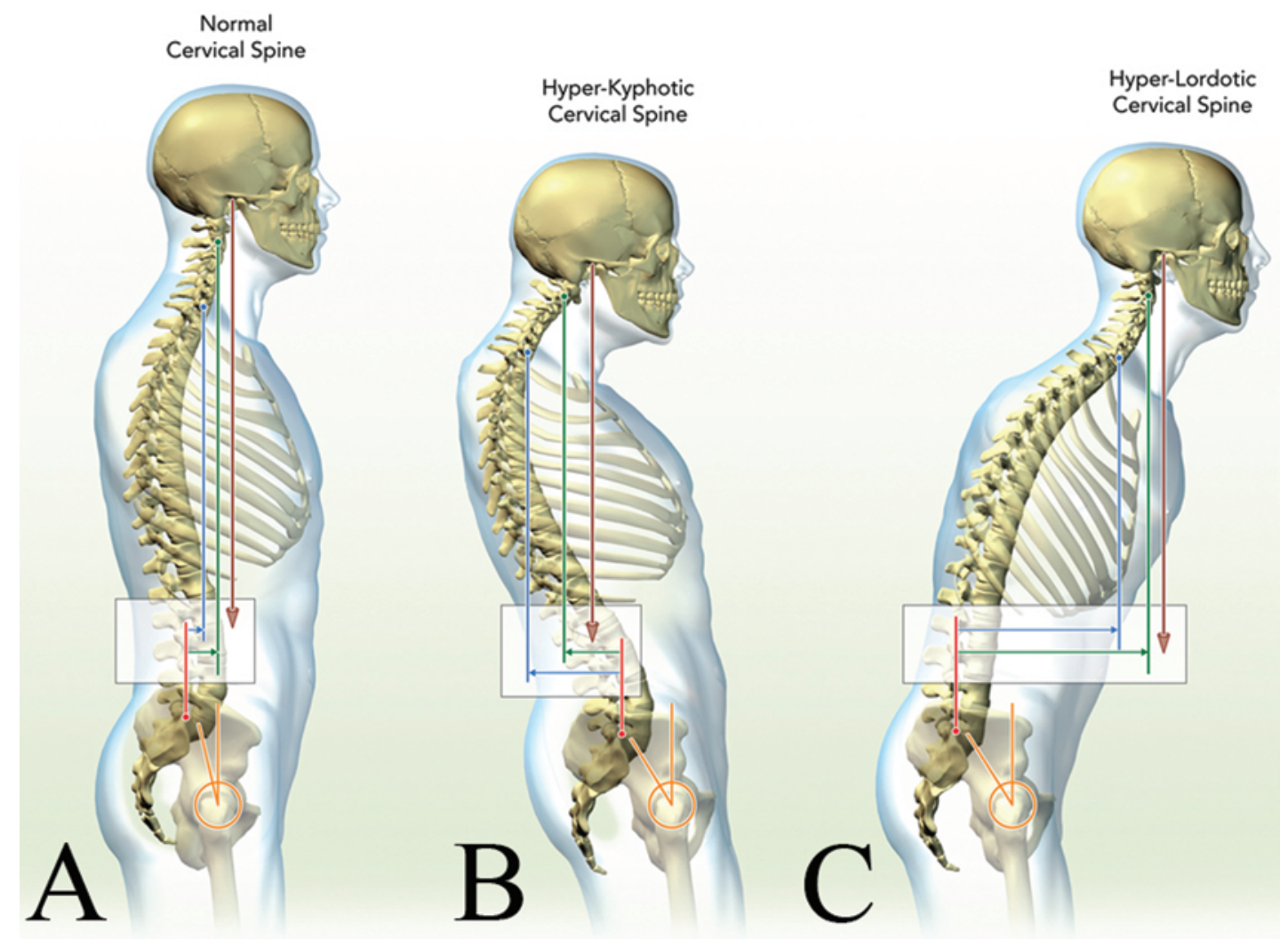

FIG. 11. Proper sagittal alignment facilitates posture maintenance, and poor alignment can lead to compensatory mechanisms that alter alignment parameters of the cervical spine. An elevated pelvic tilt is produced by either cervical kyphosis or global sagittal malalignment, but pelvic tilt due to cervical kyphosis is usually accompanied by lumbar hyperlordosis.

terior arch-facet complex tends to cause a shift in load bearing from the posterior column to the anterior column. Over time, this shift places added stress on the cervical musculature, requiring constant contraction to maintain an upright head posture, which results in fatigue and pain. Cervical kyphosis occurs as the load is shifted anteriorly, and as the discs and vertebral bodies become wedged, it progresses to greater sagittal malalignment. This kyphosis can then lead to cervical myelopathy due to the curve of the spine as discussed above, thus creating worsened myelopathy from a surgical treatment that was intended to treat myelopathy. The kyphosis can then simultaneously contribute to the development of ASD due to the increased loads and pressure anteriorly, possibly adversely affecting the discs.

Furthermore, it is not always possible to correct cervical lordotic alignment in the subaxial spine above C-7 through a posterior approach alone. An anterior approach with reconstruction using lordotic interbody spacers may be needed to restore the natural lordotic curve of the cervical spine. If the cervical spine is fused in the kyphotic position or posterior decompression alone is undertaken, this may lead to future myelopathy and/or ASD due to the reasons discussed above. Recent data has shown that patients who underwent 1- or 2-level corpectomies for CSM had positive long-term outcomes in terms of HRQOL and maintenance of the regional cervical lordosis. ${ }^{5}$

\section{Future Directions and Global Cervical-Pelvic Relationships}

Regional radiographic relationships have been well established in the literature regarding cervical deformities. As discussed, the T-1 slope and thoracic inlet angle, as they relate to cervical lordosis, are important parameters to consider in optimizing cervical deformity correction. ${ }^{62,102}$ However, inasmuch as these are regional relationships, they do not characterize the global relationships in the spine. A new chapter in describing cervical deformities entails understanding the relationship of the cervical spine to the pelvis.

Understanding pelvic incidence as it relates to lumbar lordosis was crucial in building our knowledge of thoracolumbar deformities. Similarly, a parameter such as the T-1 incidence can further our understanding of cervical deformities. A patient with cervical deformity can alter the T-1 slope through compensatory mechanisms such as retroverting the pelvis, thoracic hypokyphosis, and lumbar hyperlordosis (Fig. 7 lower). Patients who develop cervicothoracic deformities after thoracolumbar fusions (as in patients with proximal junctional kyphosis) cannot rely on thoracic and lumbar compensatory mechanisms, but they do rely on pelvic retroversion to improve their horizontal gaze. Unlike T-1 slope, the T-1 incidence is independent of pelvic version and thus it can be a better 

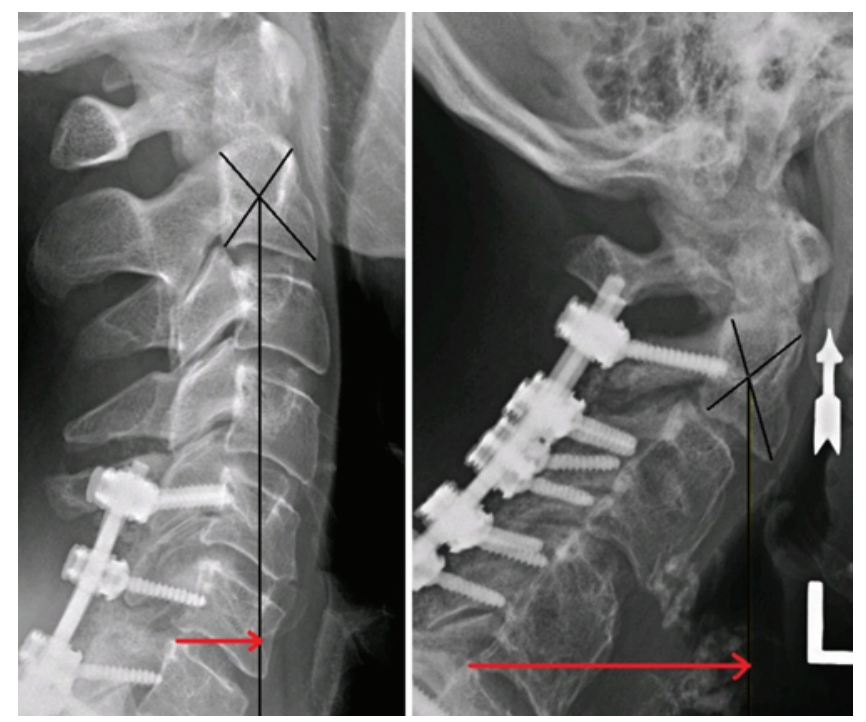

FIG. 12. Lateral radiographs of 2 different patients demonstrate how increased cervical SVA relates to poor HRQOL measures. Left: Normal cervical SVA of $20.9 \mathrm{~mm}$ with an SF-36 physical component score of 55.1 and NDI of 3 (no disability). Right: Increased cervical SVA of $59.2 \mathrm{~mm}$ with an SF-36 physical component score of 28 and NDI of 37 (severe disability).

predictor of the magnitude of cervical deformity correction necessary for optimal balance.

Another parameter that accounts for the cervicalpelvic relationship, the C-2 spino-pelvic inclination, may prove to be as important as the analogous T-1 spinopelvic inclination (T-1 tilt) in correlating with HRQOL outcomes. The goal of cervical deformity correction is to align the center of mass of the head over the pelvis, and therefore, C-2 should be likewise aligned.

Many studies have established the importance of the CBVA in cervical deformity correction. $19,53,54,86,102,110$ Generally, determining the CBVA requires a clinical photograph of the patient standing with knees locked in extension. The CBVA is not usually apparent on most standing lateral cervical radiographs. A better measure that correlates with horizontal gaze and can be visualized and measured on a standard lateral cervical radiograph would be more useful; such a measure is the C-2 slope. The horizontal tilt of the C-2 endplate on a standing lateral radiograph will correlate with the ability of a patient to maintain a horizontal gaze. The normative values of occiput-C1 and C1-2 lordosis have been established in studies of asymptomatic individuals. ${ }^{26,30}$ From the occiput to $\mathrm{C}-2$, on average, there is about $30^{\circ}$ of lordosis in a comfortable standing posture..$^{30}$ Therefore, the C-2 slope should be close to $15^{\circ}$ for a comfortable horizontal gaze (a CBVA of $10^{\circ}$ has been described as an optimal target). There can be a tremendous degree of compensation and hyperlordosis from the occiput to $\mathrm{C}-2$ and as a result a $\mathrm{C}-2$ slope as large as $50^{\circ}$ could allow for a CBVA of $10^{\circ}$ with maximal upper cervical compensation, but this degree of compensation may not be comfortable. All such parameters need to be validated in studies that correlate HRQOL outcomes following cervical deformity correction.

\section{Summary}

The cervical spine is complex and surgical management of cervical disease remains a significant challenge. An understanding of cervical biomechanics as well as the normative data for cervical alignment is necessary to manage complex cervical pathology. The cervical spine carries the load of the head and neck via a 3-column model consisting of an anterior and 2 posterior columns, which should not be confused with the 3-column model in the thoracolumbar spine consisting of anterior, middle, and posterior columns. Within the 3 columns of the cervical spine, the overall shape is lordotic, with the thoracic inlet angle playing a major role in the degree of lordotic curvature, similar to that of pelvic incidence and lumbar lordosis. The major parameters used to assess cervical spine alignment include Cobb angles, Jackson stress lines, and Harrison posterior tangent lines for sagittal curvature; gravity line (center of gravity of the head) or C-2 plumb line for SVA; and the CBVA for horizontal gaze.
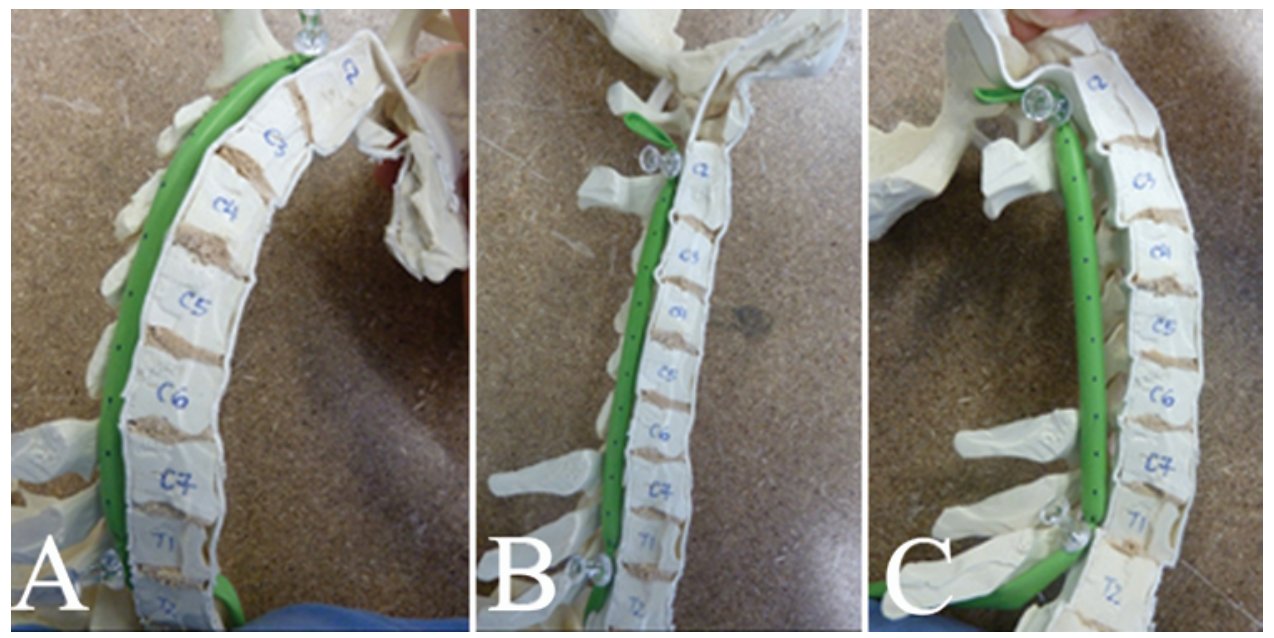

FIG. 13. Sagittal cervical spine model demonstrating spinal cord tension and length changes in response to sagittal alignment. The distance between marks (black dots) on the cord was measured and was $1.2 \mathrm{~cm}$ for kyphosis (A), $1.1 \mathrm{~cm}$ for the neutral position (B), and $1.0 \mathrm{~cm}$ for cervical lordosis with a C3-5 laminectomy (C). 

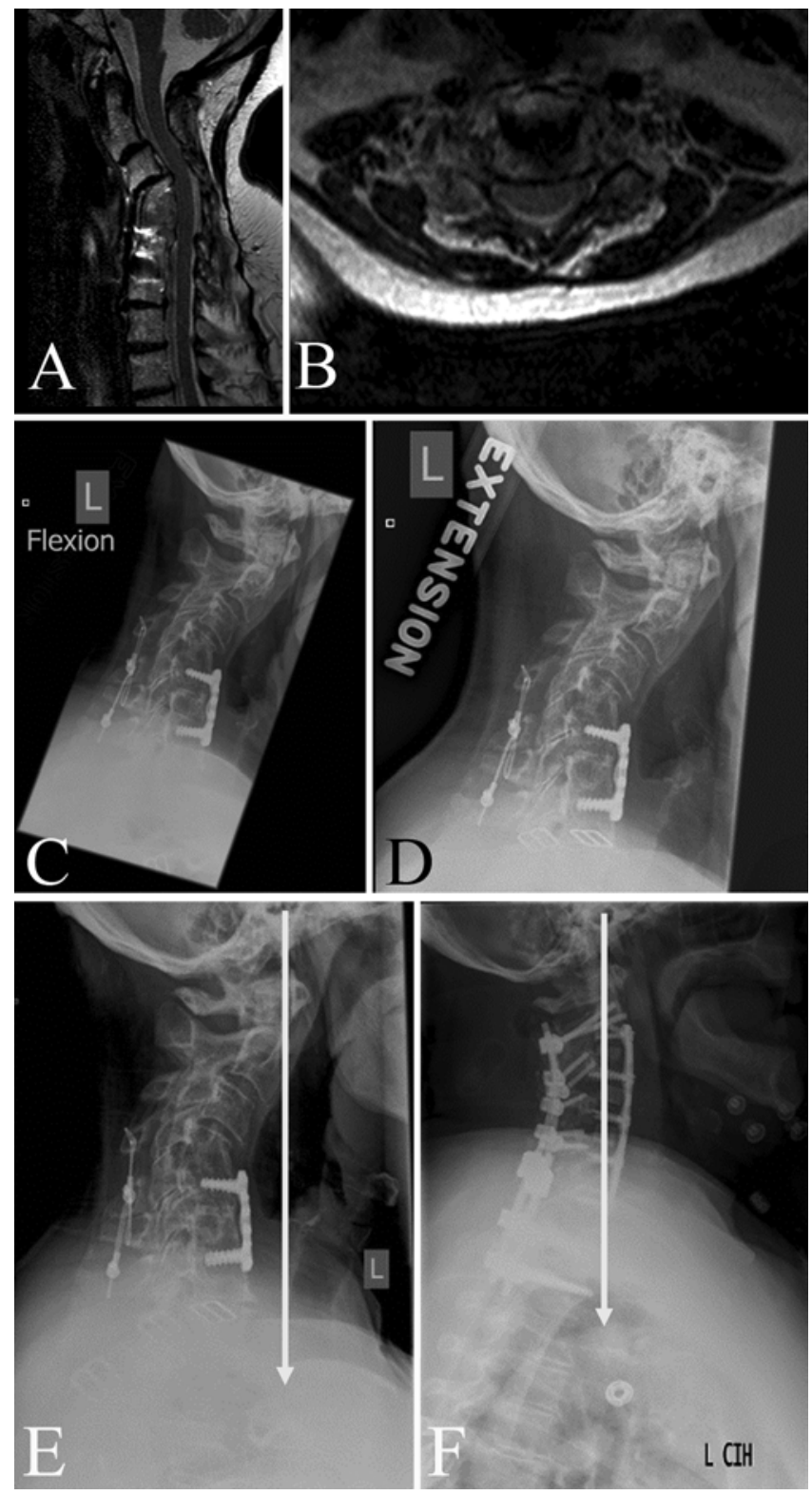

FIG. 14. Case 2. Images obtained in a 55-year-old man with progressive neck pain and myelopathy in the setting of solid fusion due to kyphosis-induced cord tension and sagittal imbalance. The patient had a surgical history of ACDF and laminectomy. On physical examination his head was flexed forward looking down, he had a spastic gait, and he was hyperreflexic with upper-extremity $4 / 5$ strength diffusely. Sagittal (A) and axial (B) MR images demonstrated spinal cord morphology indicative of tension due to kyphosis without significant compression. Flexion (C) and extension (D) lateral radiographs showed a very poor range of motion. Lateral radiographs showed preoperative cervical alignment $(E)$ and full correction of kyphosis and sagittal balance $(F)$ after a $540^{\circ}$ procedure and uncovertebral joint osteotomy.

Newer parameters include thoracic inlet angle, cervical tilt, neck tilt, and cranial tilt. It has been shown that these parameters affect the alignment of the cervical spine. To maintain neck tilt at approximately $44^{\circ}$ to reduce muscle energy expenditure, the thoracic inlet angle increases or decreases based on changes in T-1 slope and cervical lordosis. These relationships form a baseline founda- tion for future investigation as well as surgical planning of cervical fusions. Furthermore, it is very important to remember that the spinal regions are not independent of one another. Cervical lordosis depends on both thoracic kyphosis and lumbar lordosis. Cervical lordosis can be considered an adaptation by which the cervical spinal segment changes relative to the other spinal segments to attempt to maintain the head over the pelvis and maintain horizontal gaze. In a patient with global sagittal malalignment, cervical lordosis increases as a compensatory mechanism.

The most common type of cervical malaligment is cervical kyphosis, generally due to iatrogenic origins such as postlaminectomy kyphosis. The main objectives of cervical deformity surgery include the maintenance/ restoration of horizontal gaze, decompression of neural elements, and an overall effort to reestablish the normative alignment of the cervical spine. Despite the current literature reporting positive outcomes with restoring cervical lordosis, a clear consensus on the optimal amount of cervical lordosis is still lacking. However, it has become a general rule to at least correct the cervical kyphosis to a neutral position. To completely evaluate cervical alignment in the context of the entire spine, full standing radiographs are needed. This is critical due to the cervical spine adapting to the rest of the spine as discussed above. In addition, the relationship between HRQOL and cervical alignment, particularly cervical SVA, has not been discussed in the literature. Of the studies that do exist, maintaining or improving segmental cervical sagittal alignment correlates more with postoperative clinical outcomes than overall cervical lordosis via Cobb angles. The CBVA measurement is a powerful objective way to assess a patient's horizontal gaze and has been shown to be greatly improved following cervical sagittal malalignment correction. To our knowledge, the only study addressing cervical SVA and HRQOL has found that an increasing SVA is correlated with poor clinical outcomes.

Adjacent-segment disease continues to be very controversial as studies are still attempting to determine if ASD is the natural course of the spine or if adjacent spinal fusion contributes directly to ASD. Various biomechanical studies have proposed mechanisms for the lumbar spine that include increased loading and excessive motion of the intervertebral disc adjacent to the fusion site. The cervical spine is much less studied, with the only study investigating this topic concluding that postoperative cervical kyphosis may contribute to cervical ASD. Thus, maintaining or improving cervical lordosis is very important when correcting any kind of cervical deformity.

Cervical myelopathy is a serious manifestation of cervical spine disease and may be initiated or exacerbated in a patient with cervical sagittal malalignment. The deformity leads to a draping of the spinal cord against the vertebral bodies, leading to anterior spinal cord compression and increasing the longitudinal cord tension due to the cord being tethered by the dentate ligaments and cervical nerve roots. The compression and increased tension leads to an increase in medullary pressure and ultimately neuronal loss causing myelopathy. Therefore, postoperative sagittal alignment must be considered when correct- 
ing cervical deformities to prevent the onset or exacerbation of the cervical myelopathy symptoms. This is especially true when performing multilevel laminectomies in which the spine may not initially be destabilized. However, because the cervical spine relies on the posterior columns for weight bearing, resecting the posterior elements causes a shift in the load from posterior to anterior. Over time, the cervical spine becomes kyphotic due to the neck musculature constantly contracting and becoming fatigued. This may result in worsened myelopathy from a surgery originally intended to correct myelopathy.

Finally, the future directions of cervical deformity lie in assessing the spine as a whole, including the cervicalpelvic relationships. As discussed above, the T-1 slope plays a role in cervical lordosis. A patient can alter the T-1 slope through compensatory mechanisms such as retroverting the pelvis, thoracic hypokyphosis, and lumbar hyperlordosis. However, patients who develop cervicothoraic deformities after thoracolumbar fusions (as in patients with proximal junctional kyphosis) cannot rely on thoracic and lumbar compensatory mechanisms, but they do rely on pelvic retroversion to improve their horizontal gaze. Unlike T-1 slope, the T-1 incidence is independent of pelvic tilt and thus it can be a better predictor of the magnitude of cervical deformity correction necessary for optimal balance. The C-2 spino-pelvic inclination may prove to be just as useful for the cervical spine as the T-1 spino-pelvic inclination is for HRQOL, because the goal of cervical deformity surgery is to align the center of mass of the head over the pelvis, and thus C-2 should be aligned as well. The CBVA has been one of the best measures of horizontal gaze, as mentioned above. However, this measure is not generally apparent on lateral cervical radiographs. If this is the case, the $\mathrm{C}-2$ slope (horizontal tilt of the C-2 endplate) may be used to correlate the patient's ability to maintain a horizontal gaze. These concepts are in the early stages and future studies correlating them with HRQOL will expand the current understanding of cervical alignment and deformity surgery. Likewise, further investigation of the cervical spine in other areas is much needed as well, especially the relationship between the various cervical alignment parameters and HRQOL, cervical deformity, and osteotomy classification, and more standardized indications for surgery.

\section{Disclosure}

Dr. Smith serves as a consultant to Biomet and Medtronic, and received research study group support from DePuy for the International Spine Study Group. Dr. Protopsaltis serves on the Speaker's Bureau for K2M and Nemaris. Dr. Blondel serves as a consultant to Medicrea. Dr. Bess serves as a consultant to DePuy Spine, Medtronic, Lanyx, Alphatec, and Allosource; is a patent holder for Pioneer; has given lectures and/or received grants from DePuy Spine and Medtronic; and is a Board Member for Allosource. Dr. Shaffrey serves as a consultant to Medtronic, Biomet, NuVasive, and Globus, and is a patent holder for Medtronic and Biomet. Dr. Deviren serves as a consultant to NuVasive, Stryker, Medtronic, and Guidepoint. Dr. Lafage has direct stock ownership in Nemaris, serves as a consultant to Medtronic, and has overseen support of non-study-related clinical or research effort from the International Spine Study Group and Depuy. Dr. Ames serves as a consultant to DePuy, Medtronic, and Stryker; has direct stock ownership in Trans1, Visualase, and
Doctors Research Group; and has received royalties from LANX and Aesculap.

Author contributions to the study and manuscript preparation include the following. Conception and design: Scheer, Ames. Acquisition of data: Scheer, Tang. Analysis and interpretation of data: Scheer, Tang. Drafting the article: Scheer, Tang, Smith. Critically revising the article: all authors. Reviewed submitted version of manuscript: all authors. Approved the final version of the manuscript on behalf of all authors: Scheer. Study supervision: Ames.

\section{References}

1. Abumi K, Shono Y, Taneichi H, Ito M, Kaneda K: Correction of cervical kyphosis using pedicle screw fixation systems. Spine (Phila Pa 1976) 24:2389-2396, 1999

2. Albert TJ, Vacarro A: Postlaminectomy kyphosis. Spine (Phila Pa 1976) 23:2738-2745, 1998

3. Ames CP, Smith JS, Scheer JK, Bess S, Bederman SS, Deviren V, et al: Impact of spinopelvic alignment on decision making in deformity surgery in adults. A review. J Neurosurg Spine 16:547-564, 2012

4. An HS, Vaccaro A, Cotler JM, Lin S: Spinal disorders at the cervicothoracic junction. Spine (Phila Pa 1976) 19:25572564, 1994

5. Andaluz N, Zuccarello M, Kuntz C: Long-term follow-up of cervical radiographic sagittal spinal alignment after 1- and 2-level cervical corpectomy for the treatment of spondylosis of the subaxial cervical spine causing radiculomyelopathy or myelopathy: a retrospective study. Clinical article. J Neurosurg Spine 16:2-7, 2012

6. Baba H, Furusawa N, Imura S, Kawahara N, Tsuchiya H, Tomita K: Late radiographic findings after anterior cervical fusion for spondylotic myeloradiculopathy. Spine (Phila Pa 1976) 18:2167-2173, 1993

7. Beier G, Schuck M, Schuller E, Spann W: Determination of Physical Data of the Head I. Center of Gravity and Moments of Inertia of Human Heads. Munich: Institute of Forensic Medicine, University of Munich, 1979, p 44

8. Belanger TA, Milam RA IV, Roh JS, Bohlman HH: Cervicothoracic extension osteotomy for chin-on-chest deformity in ankylosing spondylitis. J Bone Joint Surg Am 87:1732-1738, 2005

9. Bernhardt M, Bridwell KH: Segmental analysis of the sagittal plane alignment of the normal thoracic and lumbar spines and thoracolumbar junction. Spine (Phila Pa 1976) 14:717-721, 1989

10. Boachie-Adjei O: Role and technique of eggshell osteotomies and vertebral column resections in the treatment of fixed sagittal imbalance. Instr Course Lect 55:583-589, 2006

11. Booth KC, Bridwell KH, Lenke LG, Baldus CR, Blanke KM: Complications and predictive factors for the successful treatment of flatback deformity (fixed sagittal imbalance). Spine (Phila Pa 1976) 24:1712-1720, 1999

12. Bridwell KH, Baldus C, Berven S, Edwards C II, Glassman $\mathrm{S}$, Hamill C, et al: Changes in radiographic and clinical outcomes with primary treatment adult spinal deformity surgeries from two years to three- to five-years follow-up. Spine (Phila Pa 1976) 35:1849-1854, 2010

13. Briggs AM, Wrigley TV, Tully EA, Adams PE, Greig AM, Bennell KL: Radiographic measures of thoracic kyphosis in osteoporosis: Cobb and vertebral centroid angles. Skeletal Radiol 36:761-767, 2007

14. Buckwalter JA: Aging and degeneration of the human intervertebral disc. Spine (Phila Pa 1976) 20:1307-1314, 1995

15. Butler JC, Whitecloud TS III: Postlaminectomy kyphosis. Causes and surgical management. Orthop Clin North Am 23: 505-511, 1992

16. Chi JH, Tay B, Stahl D, Lee R: Complex deformities of the cervical spine. Neurosurg Clin N Am 18:295-304, 2007 
17. Denis F: The three column spine and its significance in the classification of acute thoracolumbar spinal injuries. Spine (Phila Pa 1976) 8:817-831, 1983

18. Deutsch H, Haid RW, Rodts GE, Mummaneni PV: Postlaminectomy cervical deformity. Neurosurg Focus 15(3):E5, 2003

19. Deviren V, Scheer JK, Ames CP: Technique of cervicothoracic junction pedicle subtraction osteotomy for cervical sagittal imbalance: report of 11 cases. Clinical article. J Neurosurg Spine 15:174-181, 2011

20. Djurasovic MO, Carreon LY, Glassman SD, Dimar JR II, Puno RM, Johnson JR: Sagittal alignment as a risk factor for adjacent level degeneration: a case-control study. Orthopedics 31:546, 2008

21. Eck JC, Humphreys SC, Lim TH, Jeong ST, Kim JG, Hodges $\mathrm{SD}$, et al: Biomechanical study on the effect of cervical spine fusion on adjacent-level intradiscal pressure and segmental motion. Spine (Phila Pa 1976) 27:2431-2434, 2002

22. El Fegoun AB, Schwab F, Gamez L, Champain N, Skalli W, Farcy JP: Center of gravity and radiographic posture analysis: a preliminary review of adult volunteers and adult patients affected by scoliosis. Spine (Phila Pa 1976) 30:1535-1540, 2005

23. Etame AB, Wang AC, Than KD, La Marca F, Park P: Outcomes after surgery for cervical spine deformity: review of the literature. Neurosurg Focus 28(3):E14, 2010

24. Ferch RD, Shad A, Cadoux-Hudson TA, Teddy PJ: Anterior correction of cervical kyphotic deformity: effects on myelopathy, neck pain, and sagittal alignment. J Neurosurg 100 (1 Suppl Spine):13-19, 2004

25. Gangnet N, Pomero V, Dumas R, Skalli W, Vital JM: Variability of the spine and pelvis location with respect to the gravity line: a three-dimensional stereoradiographic study using a force platform. Surg Radiol Anat 25:424-433, 2003

26. Gay RE: The curve of the cervical spine: variations and significance. J Manipulative Physiol Ther 16:591-594, 1993

27. Glassman SD, Berven S, Bridwell K, Horton W, Dimar JR: Correlation of radiographic parameters and clinical symptoms in adult scoliosis. Spine (Phila Pa 1976) 30:682-688, 2005

28. Glassman SD, Bridwell K, Dimar JR, Horton W, Berven S, Schwab F: The impact of positive sagittal balance in adult spinal deformity. Spine (Phila Pa 1976) 30:2024-2029, 2005

29. Gore DR: Roentgenographic findings in the cervical spine in asymptomatic persons: a ten-year follow-up. Spine (Phila Pa 1976) 26:2463-2466, 2001

30. Gore DR, Sepic SB, Gardner GM: Roentgenographic findings of the cervical spine in asymptomatic people. Spine (Phila Pa 1976) 11:521-524, 1986

31. Gore DR, Sepic SB, Gardner GM, Murray MP: Neck pain: a long-term follow-up of 205 patients. Spine (Phila Pa 1976) 12:1-5, 1987

32. Guérin P, Obeid I, Gille O, Bourghli A, Luc S, Pointillart V, et al: Sagittal alignment after single cervical disc arthroplasty. J Spinal Disord Tech 25:10-16, 2012

33. Hardacker JW, Shuford RF, Capicotto PN, Pryor PW: Radiographic standing cervical segmental alignment in adult volunteers without neck symptoms. Spine (Phila Pa 1976) 22:1472-1480, 1997

34. Harrison DE, Harrison DD, Cailliet R, Troyanovich SJ, Janik TJ, Holland B: Cobb method or Harrison posterior tangent method: which to choose for lateral cervical radiographic analysis. Spine (Phila Pa 1976) 25:2072-2078, 2000

35. Herman JM, Sonntag VKH: Cervical corpectomy and plate fixation for postlaminectomy kyphosis. J Neurosurg 80:963970, 1994

36. Hilibrand AS, Carlson GD, Palumbo MA, Jones PK, Bohlman HH: Radiculopathy and myelopathy at segments adjacent to the site of a previous anterior cervical arthrodesis. J Bone Joint Surg Am 81:519-528, 1999

37. Hilibrand AS, Robbins M: Adjacent segment degeneration and adjacent segment disease: the consequences of spinal fusion? Spine J 4 (6 Suppl):190S-194S, 2004

38. Hilibrand AS, Tannenbaum DA, Graziano GP, Loder RT, Hensinger RN: The sagittal alignment of the cervical spine in adolescent idiopathic scoliosis. J Pediatr Orthop 15:627632,1995

39. Hutton WC, Toribatake Y, Elmer WA, Ganey TM, Tomita K, Whitesides TE: The effect of compressive force applied to the intervertebral disc in vivo. A study of proteoglycans and collagen. Spine (Phila Pa 1976) 23:2524-2537, 1998

40. Hwang SW, Samdani AF, Tantorski M, Cahill P, Nydick J, Fine A, et al: Cervical sagittal plane decompensation after surgery for adolescent idiopathic scoliosis: an effect imparted by postoperative thoracic hypokyphosis. Clinical article. J Neurosurg Spine 15:491-496, 2011

41. Iida H, Tachibana S: Spinal cord intramedullary pressure: direct cord traction test. Neurol Med Chir (Tokyo) 35:75-77, 1995

42. Ishihara H, Kanamori M, Kawaguchi Y, Nakamura H, Kimura T: Adjacent segment disease after anterior cervical interbody fusion. Spine J 4:624-628, 2004

43. Jackson R: The Cervical Syndrome, ed 2. Springfield, IL: Charles C. Thomas, 1958

44. Jackson RP, McManus AC: Radiographic analysis of sagittal plane alignment and balance in standing volunteers and patients with low back pain matched for age, sex, and size. A prospective controlled clinical study. Spine (Phila Pa 1976) 19:1611-1618, 1994

45. Jagannathan J, Shaffrey CI, Oskouian RJ, Dumont AS, Herrold C, Sansur CA, et al: Radiographic and clinical outcomes following single-level anterior cervical discectomy and allograft fusion without plate placement or cervical collar. J Neurosurg Spine 8:420-428, 2008

46. Jarzem PF, Quance DR, Doyle DJ, Begin LR, Kostuik JP: Spinal cord tissue pressure during spinal cord distraction in dogs. Spine (Phila Pa 1976) 17 (8 Suppl):S227-S234, 1992

47. Javedan SP, Dickman CA: Cause of adjacent-segment disease after spinal fusion. Lancet 354:530-531, 1999

48. Jenkins LA, Capen DA, Zigler JE, Nelson RW, Nagelberg S: Cervical spine fusions for trauma. A long-term radiographic and clinical evaluation. Orthop Rev Suppl:13-19, 1994

49. Kaptain GJ, Simmons NE, Replogle RE, Pobereskin L: Incidence and outcome of kyphotic deformity following laminectomy for cervical spondylotic myelopathy. J Neurosurg 93 (2 Suppl):199-204, 2000

50. Katsuura A, Hukuda S, Saruhashi Y, Mori K: Kyphotic malalignment after anterior cervical fusion is one of the factors promoting the degenerative process in adjacent intervertebral levels. Eur Spine J 10:320-324, 2001

51. Kawakami M, Tamaki T, Yoshida M, Hayashi N, Ando M, Yamada H: Axial symptoms and cervical alignments after cervical anterior spinal fusion for patients with cervical myelopathy. J Spinal Disord 12:50-56, 1999

52. Kepler CK, Hilibrand AS: Management of adjacent segment disease after cervical spinal fusion. Orthop Clin North Am 43:53-62, 2012

53. Kim KT, Lee SH, Son ES, Kwack YH, Chun YS, Lee JH: Surgical treatment of "chin-on-pubis" deformity in a patient with ankylosing spondylitis: a case report of consecutive cervical, thoracic, and lumbar corrective osteotomies. Spine (Phila Pa 1976) 37:E1017-E1021, 2012

54. Kim KT, Suk KS, Cho YJ, Hong GP, Park BJ: Clinical outcome results of pedicle subtraction osteotomy in ankylosing spondylitis with kyphotic deformity. Spine (Phila Pa 1976) 27:612-618, 2002

55. Kim YJ, Bridwell KH, Lenke LG, Cheh G, Baldus C: Results of lumbar pedicle subtraction osteotomies for fixed sagittal imbalance: a minimum 5-year follow-up study. Spine (Phila Pa 1976) 32:2189-2197, 2007

56. Kitahara Y, Iida H, Tachibana S: Effect of spinal cord stretch- 
ing due to head flexion on intramedullary pressure. Neurol Med Chir (Tokyo) 35:285-288, 1995

57. Klineberg E: Cervical spondylotic myelopathy: a review of the evidence. Orthop Clin North Am 41:193-202, 2010

58. Knott PT, Mardjetko SM, Techy F: The use of the T1 sagittal angle in predicting overall sagittal balance of the spine. Spine J 10:994-998, 2010

59. Kumar MN, Baklanov A, Chopin D: Correlation between sagittal plane changes and adjacent segment degeneration following lumbar spine fusion. Eur Spine J 10:314-319, 2001

60. Kwon B, Kim DH, Marvin A, Jenis LG: Outcomes following anterior cervical discectomy and fusion: the role of interbody disc height, angulation, and spinous process distance. J Spinal Disord Tech 18:304-308, 2005

61. Lafage V, Ames C, Schwab F, Klineberg E, Akbarnia B, Smith $\mathrm{J}$, et al: Changes in thoracic kyphosis negatively impact sagittal alignment after lumbar pedicle subtraction osteotomy: a comprehensive radiographic analysis. Spine (Phila Pa 1976) 37:E180-E187, 2012

62. Lafage V, Schwab F, Skalli W, Hawkinson N, Gagey PM, Ondra S, et al: Standing balance and sagittal plane spinal deformity: analysis of spinopelvic and gravity line parameters. Spine (Phila Pa 1976) 33:1572-1578, 2008

63. Langeloo DD, Journee HL, Pavlov PW, de Kleuver M: Cervical osteotomy in ankylosing spondylitis: evaluation of new developments. Eur Spine J 15:493-500, 2006

64. Lee SH, Kim KT, Seo EM, Suk KS, Kwack YH, Son ES: The influence of thoracic inlet alignment on the craniocervical sagittal balance in asymptomatic adults. J Spinal Disord Tech 25:E41-E47, 2012

65. Legaye J, Duval-Beaupere G: Gravitational forces and sagittal shape of the spine. Clinical estimation of their relations. Int Orthop 32:809-816, 2008

66. Lorenz M, Patwardhan A, Vanderby R Jr: Load-bearing characteristics of lumbar facets in normal and surgically altered spinal segments. Spine (Phila Pa 1976) 8:122-130, 1983

67. Louis R: Spinal stability as defined by the three-column spine concept. Anat Clin 7:33-42, 1985

68. Lu DC, Chou D: Flatback syndrome. Neurosurg Clin N Am 18:289-294, 2007

69. Mac-Thiong JM, Transfeldt EE, Mehbod AA, Perra JH, Denis F, Garvey TA, et al: Can c7 plumbline and gravity line predict health related quality of life in adult scoliosis? Spine (Phila Pa 1976) 34:E519-E527, 2009

70. Maiman DJ, Kumaresan S, Yoganandan N, Pintar FA: Biomechanical effect of anterior cervical spine fusion on adjacent segments. Biomed Mater Eng 9:27-38, 1999

71. Maldonado CV, Paz RD, Martin CB: Adjacent-level degeneration after cervical disc arthroplasty versus fusion. Eur Spine J 20 (Suppl 3):403-407, 2011

72. Matsunaga S, Kabayama S, Yamamoto T, Yone K, Sakou T, Nakanishi K: Strain on intervertebral discs after anterior cervical decompression and fusion. Spine (Phila Pa 1976) 24:670-675, 1999

73. Matz PG, Anderson PA, Holly LT, Groff MW, Heary RF, Kaiser MG, et al: The natural history of cervical spondylotic myelopathy. J Neurosurg Spine 11:104-111, 2009

74. McAviney J, Schulz D, Bock R, Harrison DE, Holland B: Determining the relationship between cervical lordosis and neck complaints. J Manipulative Physiol Ther 28:187-193, 2005

75. McMaster MJ: Osteotomy of the cervical spine in ankylosing spondylitis. J Bone Joint Surg Br 79:197-203, 1997

76. Mummaneni PV, Deutsch H, Mummaneni VP: Cervicothoracic kyphosis. Neurosurg Clin N Am 17:277-287, 2006

77. Mummaneni PV, Dhall SS, Rodts GE, Haid RW: Circumferential fusion for cervical kyphotic deformity. Clinical article. J Neurosurg Spine 9:515-521, 2008

78. Nachemson A: Lumbar intradiscal pressure. Experimental studies on post-mortem material. Acta Orthop Scand Suppl 43:1-104, 1960
79. Naderi S, Ozgen S, Pamir MN, Ozek MM, Erzen C: Cervical spondylotic myelopathy: surgical results and factors affecting prognosis. Neurosurgery 43:43-50, 1998

80. Nottmeier EW, Deen HG, Patel N, Birch B: Cervical kyphotic deformity correction using 360-degree reconstruction. J Spinal Disord Tech 22:385-391, 2009

81. Oda I, Cunningham BW, Buckley RA, Goebel MJ, Haggerty CJ, Orbegoso CM, et al: Does spinal kyphotic deformity influence the biomechanical characteristics of the adjacent motion segments? An in vivo animal model. Spine (Phila Pa 1976) 24:2139-2146, 1999

82. O’Shaughnessy BA, Liu JC, Hsieh PC, Koski TR, Ganju A, Ondra SL: Surgical treatment of fixed cervical kyphosis with myelopathy. Spine (Phila Pa 1976) 33:771-778, 2008

83. Pal GP, Sherk HH: The vertical stability of the cervical spine. Spine (Phila Pa 1976) 13:447-449, 1988

84. Park DH, Ramakrishnan P, Cho TH, Lorenz E, Eck JC, Humphreys SC, et al: Effect of lower two-level anterior cervical fusion on the superior adjacent level. J Neurosurg Spine 7:336340,2007

85. Park P, Garton HJ, Gala VC, Hoff JT, McGillicuddy JE: Adjacent segment disease after lumbar or lumbosacral fusion: review of the literature. Spine (Phila Pa 1976) 29:1938-1944, 2004

86. Pigge RR, Scheerder FJ, Smit TH, Mullender MG, van Royen $\mathrm{BJ}$ : Effectiveness of preoperative planning in the restoration of balance and view in ankylosing spondylitis. Neurosurg Focus 24(1):E7, 2008

87. Polly DW Jr, Kilkelly FX, McHale KA, Asplund LM, Mulligan M, Chang AS: Measurement of lumbar lordosis. Evaluation of intraobserver, interobserver, and technique variability. Spine (Phila Pa 1976) 21:1530-1536, 1996

88. Prasarn ML, Baria D, Milne E, Latta L, Sukovich W: Adjacent-level biomechanics after single versus multilevel cervical spine fusion. Laboratory investigation. J Neurosurg Spine 16:172-177, 2012

89. Ragab AA, Escarcega AJ, Zdeblick TA: A quantitative analysis of strain at adjacent segments after segmental immobilization of the cervical spine. J Spinal Disord Tech 19:407-410, 2006

90. Rahm MD, Hall BB: Adjacent-segment degeneration after lumbar fusion with instrumentation: a retrospective study. J Spinal Disord 9:392-400, 1996

91. Rihn JA, Lawrence J, Gates C, Harris E, Hilibrand AS: Adjacent segment disease after cervical spine fusion. Instr Course Lect 58:747-756, 2009

92. Schwab F, Farcy JP, Bridwell K, Berven S, Glassman S, Harrast J, et al: A clinical impact classification of scoliosis in the adult. Spine (Phila Pa 1976) 31:2109-2114, 2006

93. Schwab F, Lafage V, Boyce R, Skalli W, Farcy JP: Gravity line analysis in adult volunteers: age-related correlation with spinal parameters, pelvic parameters, and foot position. Spine (Phila Pa 1976) 31:E959-E967, 2006

94. Schwab FJ, Smith VA, Biserni M, Gamez L, Farcy JP, Pagala M: Adult scoliosis: a quantitative radiographic and clinical analysis. Spine (Phila Pa 1976) 27:387-392, 2002

95. Schwab JS, Diangelo DJ, Foley KT: Motion compensation associated with single-level cervical fusion: where does the lost motion go? Spine (Phila Pa 1976) 31:2439-2448, 2006

96. Seo M, Choi D: Adjacent segment disease after fusion for cervical spondylosis; myth or reality? Br J Neurosurg 22: 195-199, 2008

97. Shimizu K, Nakamura M, Nishikawa Y, Hijikata S, Chiba K, Toyama Y: Spinal kyphosis causes demyelination and neuronal loss in the spinal cord: a new model of kyphotic deformity using juvenile Japanese small game fowls. Spine (Phila Pa 1976) 30:2388-2392, 2005

98. Singer KP, Jones TJ, Breidahl PD: A comparison of radiographic and computer-assisted measurements of thoracic and thoracolumbar sagittal curvature. Skeletal Radiol 19:21-26, 1990 


\section{A review of cervical spine alignment}

99. Smith JS, Shaffrey CI, Lafage V, Blondel B, Schwab F, Hostin R, et al: Spontaneous improvement of cervical alignment after correction of global sagittal balance following pedicle subtraction osteotomy. Clinical article. J Neurosurg Spine 17:300-307, 2012

100. Song KJ, Choi BW, Jeon TS, Lee KB, Chang H: Adjacent segment degenerative disease: is it due to disease progression or a fusion-associated phenomenon? Comparison between segments adjacent to the fused and non-fused segments. Eur Spine J 20:1940-1945, 2011

101. Steinmetz MP, Stewart TJ, Kager CD, Benzel EC, Vaccaro AR: Cervical deformity correction. Neurosurgery 60 (1 Supp1 1):S90-S97, 2007

102. Suk KS, Kim KT, Lee SH, Kim JM: Significance of chinbrow vertical angle in correction of kyphotic deformity of ankylosing spondylitis patients. Spine (Phila Pa 1976) 28: 2001-2005, 2003

103. Tachibana S, Kitahara Y, Iida H, Yada K: Spinal cord intramedullary pressure. A possible factor in syrinx growth. Spine (Phila Pa 1976) 19:2174-2179, 1994

104. Tang JA, Scheer JK, Smith JS, Deviren V, Bess S, Hart RA, et al: The impact of standing regional cervical sagittal alignment on outcomes in posterior cervical fusion surgery. Neurosurgery 71:662-669, 2012

105. Tracy JA, Bartleson JD: Cervical spondylotic myelopathy. Neurologist 16: 176-187, 2010

106. Uchida K, Nakajima H, Sato R, Yayama T, Mwaka ES, Kobayashi S, et al: Cervical spondylotic myelopathy associated with kyphosis or sagittal sigmoid alignment: outcome after anterior or posterior decompression. Clinical article. J Neurosurg Spine 11:521-528, 2009

107. Van Royen BJ, Toussaint HM, Kingma I, Bot SD, Caspers M, Harlaar J, et al: Accuracy of the sagittal vertical axis in a standing lateral radiograph as a measurement of balance in spinal deformities. Eur Spine J 7:408-412, 1998

108. Villavicencio AT, Babuska JM, Ashton A, Busch E, Roeca C, Nelson EL, et al: Prospective, randomized, double-blind clinical study evaluating the correlation of clinical outcomes and cervical sagittal alignment. Neurosurgery 68:1309-1316, 2011

109. Wang VY, Chou D: The cervicothoracic junction. Neurosurg Clin N Am 18:365-371, 2007

110. Wang Y, Zhang Y, Mao K, Zhang X, Wang Z, Zheng G, et al: Transpedicular bivertebrae wedge osteotomy and discectomy in lumbar spine for severe ankylosing spondylitis. J Spinal Disord Tech 23:186-191, 2010

111. Yoganandan N, Maiman DJ, Guan Y, Pintar F: Importance of physical properties of the human head on head-neck injury metrics. Traffic Inj Prev 10:488-496, 2009

112. Yoshida G, Kamiya M, Yoshihara H, Kanemura T, Kato F, Yukawa Y, et al: Subaxial sagittal alignment and adjacentsegment degeneration after atlantoaxial fixation performed using C-1 lateral mass and C-2 pedicle screws or transarticular screws. Clinical article. J Neurosurg Spine 13:443-450, 2010

113. Yoshimoto H, Ito M, Abumi K, Kotani Y, Shono Y, Takada $\mathrm{T}$, et al: A retrospective radiographic analysis of subaxial sagittal alignment after posterior C1-C2 fusion. Spine (Phila Pa 1976) 29: $175-181,2004$

114. Zdeblick TA, Bohlman HH: Cervical kyphosis and myelopathy. Treatment by anterior corpectomy and strut-grafting. J Bone Joint Surg Am 71:170-182, 1989

115. Zheng X, Chaudhari R, Wu C, Mehbod AA, Transfeldt EE, Winter RB: Repeatability test of C7 plumb line and gravity line on asymptomatic volunteers using an optical measurement technique. Spine (Phila Pa 1976) 35:E889-E894, 2010

Manuscript submitted August 31, 2012.

Accepted April 22, 2013.

Please include this information when citing this paper: published online June 14, 2013; DOI: 10.3171/2013.4.SPINE12838.

Address correspondence to: Justin K. Scheer, B.S., UC San Diego School of Medicine, 9500 Gilman Dr., La Jolla, CA 92093. email: jscheer@ucsd.edu. 